\title{
A SIMPLE ANALYTICAL METHOD FOR EVALUATION OF FLEXIBLE ROCKFALL BARRIER PART 1: WORKING MECHANISM AND ANALYTICAL SOLUTION
}

\author{
Z.X. Yu ${ }^{1,2}$, Y.K. Qiao ${ }^{1}$, L. Zhao ${ }^{1}$, H. Xu ${ }^{1 *}$, S.C. Zhao ${ }^{1,2}$ and Y.P. Liu ${ }^{3}$ \\ ${ }^{I}$ School of Civil Engineering, Southwest Jiaotong University, Chengdu, China \\ ${ }^{2}$ National Engineering Laboratory for prevention and control of geological disasters in land transportation, \\ Chengdu, China \\ ${ }^{3}$ Department of Civil and Environmental Engineering, The Hong Kong Polytechnic University, Hung Hom, \\ Kowloon, Hong Kong, China \\ *(Corresponding author: E-mail: xuhu@home.swjtu.edu.cn)
}

Received: 4 January 2017; Revised: 25 May 2017; Accepted: 5 June 2017

\begin{abstract}
The flexible rockfall barrier system exhibits large deflection and complex contact behaviors such that sophisticated finite element method and full-scale test are widely used to design this kind of structures, which causes inconvenient for most engineers. In this paper, a simple analytical method is proposed for fast evaluation of the performance of the flexible rockfall barrier system on the basis of system deflection characteristics observed in the full-scale impact tests and, the component deflection characteristics from component tests such as the puncturing deflection of steel wire-ring net, elongation of energy dissipating device, sliding movement of supporting rope and rotation of support structure. The equation for prediction of large deflection of flexible rockfall barrier system was established. The overall deflection is contributed by its components and therefore the analytical solutions for calculation of component deflections were derived based on the space geometry analysis and verified by component tests. The analytical solution for steel wire-ring nets were validated by 17 puncturing tests and the maximum difference was less than $7.4 \%$. Using the discrete ring net model, an explicit dynamic method was employed to simulate the nonlinear behaviors of flexible rockfall barriers with different design energies, i.e. $2000 \mathrm{~kJ}, 3500 \mathrm{~kJ}$ and $5000 \mathrm{~kJ}$. The deflection of each component and the overall deflections from analytical solutions were compared with the numerical simulations with the maximum difference less than $7.9 \%$. Thus, the proposed analysis solution for evaluation of large deflection of flexible rockfall barrier system is valid and ready for engineering design. A companion paper is presented in part two separately with full-scale test for further verification of the proposed method.
\end{abstract}

Keywords: flexible rockfall barrier, impact, buffer performance, large deflection, analytical solution, full-scale test

DOI: $10.18057 /$ IJASC.2018.14.2.1

\section{INTRODUCTION}

Flexible rockfall barrier is extensively used as geological disaster protection measure, which is composed of steel wire-ring nets, support structures and energy dissipating devices, using large deformation to achieve buffering and energy dissipation [1]. As shown in Figure 1, when rockfalls impact the flexible rockfall barrier, the impact force will be induced on the steel wire-ring net and then transmit to the support ropes with which the energy dissipating devices are attached. The devices undergo inelastic deformation such that energy dissipation and interception protection are realized. The whole process is accompanied by highly nonlinear mechanical behaviors such as large deformation, significant sliding, material yielding, contact and separation. This process is essentially a conversion between the work and the energy as expressed in Eq. 1. 



(a) Maximum deflection
(b) Deformed shape of energy
(c)Final state
of system
dissipating device
of system

Figure 1. Work Process of Flexible Rockfall Barrier System

$$
\begin{aligned}
& \frac{1}{2} m v^{2}+E_{\mathrm{g}}=\int_{0}^{s_{\max }} F(s) d s \\
& E_{\text {total }}=\alpha F_{\max } s_{\max }
\end{aligned}
$$

in which, $F$ is the impact force on the system; $s$ is the impact deformation of system; $m$ is the mass of rockfall; $v$ is the velocity of rockfall; $E_{\mathrm{g}}$ is the gravity work after the impact between rockfall and system, depending on the buffer distance; $E_{\text {total }}$ is the total energy of rockfall; $F_{\max }$ is the maximum impact force; $s_{\max }$ is the maximum deformation; $\alpha$ is an empirical coefficient obtained from the tests, ranging from 0.3 to 0.35 .

The maximum impact force $F_{\max }$ and the maximum deformation $s_{\max }$ are two important variables for assessment of system performance. The design of $F_{\max }$ and $s_{\max }$ within a limit means not only the demand of the bearing capacity of the system, but also the demand of protection limit. For a given demand of protection requirement, the cooperative control of $F_{\max }$ and $s_{\max }$ determines the configuration of the flexible rockfall barrier system.

According to Eq. 1b, the development of deflection directly affects the buffering performance of the system. The larger of $s_{\max }$ within the design limit, the smaller of $F_{\max }$ will be obtained and as a result, the better system performance is produced. If $s_{\max }$ can be calculated efficiently, $F_{\max }$ can be calculated from Eq. 1b, and accordingly, the internal force of each component can be computed based on classical mechanics. Compared with the commonly used numerical simulation methods, the above analytical method provides a new direction for the design of flexible rockfall barrier. It is clear that if the deflection of each component could be obtained accurately at different stages, the system deflection would be well-controlled and therefore the system with optimal suitability between impact deflection and resistance would be designed. However, due to the complex behaviors of flexible rockfall barrier undergoing large deflection, the effective and simple calculation method for the impact deflection of the system is not available in the literature. 
Previous researches [2-5] show that the impact process of flexible rockfall barrier generally has three-stage deflection characteristic, as indicated in Figure 2. The first stage is that the steel-wire ring net starts from loose state to tighten state while the internal force of system is low and the energy absorbed is small. The second stage often shows significant sliding movement of support ropes, and clear tensile deformation and energy dissipation of energy dissipating devices. Many full-scale tests show that the percentage of energy consumption in the second stage is $60-80 \%$ of the whole impact energy $[6,7]$. The third stage is mainly the puncturing deflection of the ring net in the contact area with rockfall, namely bending-straight deformation of the ring net. Due to the different constraints between the rings, the ring deflection generally has two typical modes, i.e. diagonal stretching and diametrical stretching [2,3]. The elastoplastic deformation of several steel-wire rings, the friction and sliding between the rings are significant and contribute to a portion of energy dissipation. Once the above-mentioned three-stage deflections are completed, the flexible rockfall barrier will eventually show a funnel-shaped deflection, as shown in Figure 3a.

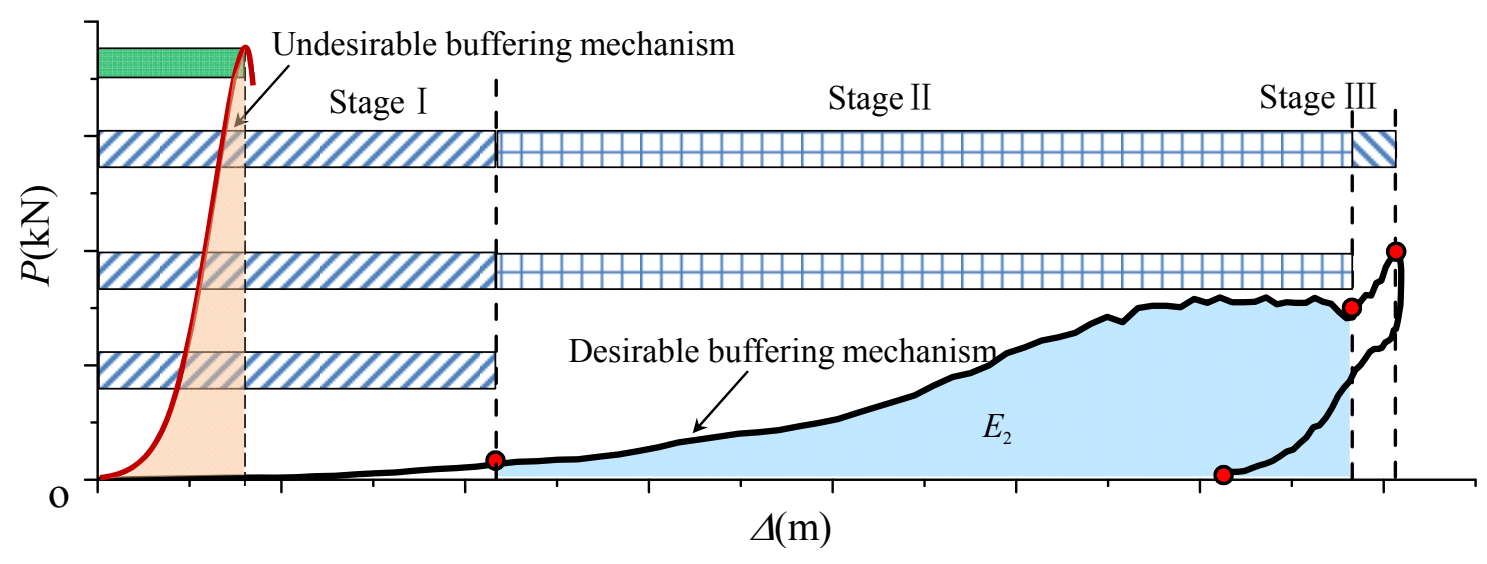

Figure 2. Three-stage Defection and Buffering Mechanism

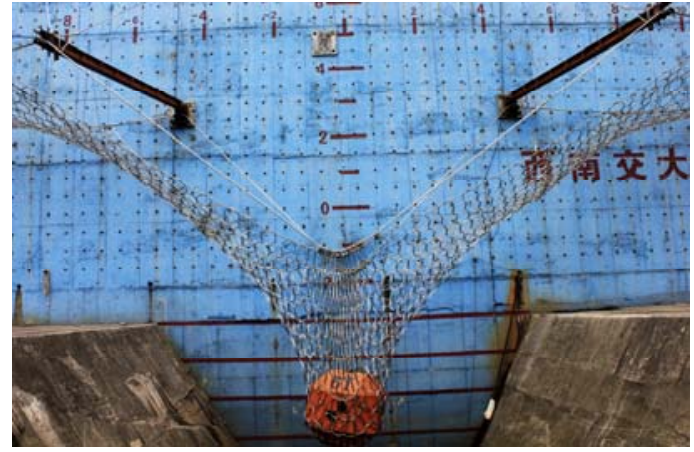

(a) Desired deformed shape

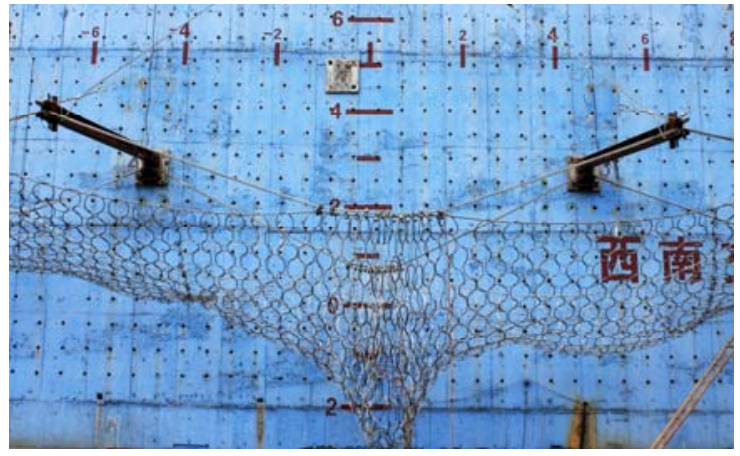

(b) Undesired deformed shape

Figure 3. Typical Deformed Shapes

However, due to different level and accuracy of design methods used, different products show very different three-stage deformed shapes, especially in the second stage in which a significant inelastic sliding movement and energy dissipation are occurred due to the mobilization of energy dissipating 
device. It can be seen from Figure 2 that the deflection in the second stage is the most prominent one during the overall system deflection. The preferred working characteristics of the energy dissipating device in practical application are tensile deformation, which is depended on the traction-sliding ability of the rope. Thus, the energy dissipating device and the rope have appropriate adaptation relationship so that the system buffering mechanism can be well-developed and leads to a better system performance. The experimental tests showed that the system performance is significantly different for different design of energy dissipating devices of two systems with same configurations of other components, as shown in Figure 3.

In recent years, the researches on study of buffering performance of flexible rockfall barrier system mainly adopted full-scale impact tests and numerical simulations [2-20]. Peila D et al. [5] conducted the full-scale impact tests of the flexible rockfall barrier system with various energy levels. For the system with energy level of $400 \mathrm{~kJ}$, the sliding behavior of the support rope is as follows. When the system was impacted by a rockfall, the net ring would slide along the support ropes. However, the motion interference between the nets and the post may easily happen, resulting in a sudden stop of sliding and insufficient development of large deformation. The impact test result also showed that the maximum deformation of the system was only $2.80 \mathrm{~m}$. Based on a field investigation in Jordan Valley, Hong Kong and combined with inverse analysis, Kwan et al. [9] found that although the flexible rockfall barrier system with a nominal energy level of $1000 \mathrm{~kJ}$ attempted to intercept a rockfall with actual impact energy of $463 \mathrm{~kJ}$, the steel post was seriously damaged, losing the ability of protection. The reason was that the energy dissipating device did not mobilize effectively, leading to inadequate buffering deformation of the system, which is not a desirable performance of the system. The measured and calculated results also showed that the impact deformation was only about $2.5 \mathrm{~m}$. Escallón et al. [10] improved the system by releasing several rings on the support rope near the post ends, and formed the bypassing length to defer the motion interference. The improved system enhances the sliding ability of support ropes and increases the buffering performance of the system. The full-scale test result showed that the maximum impact deformation was increased up to $9 \mathrm{~m}$. Unfortunately, due to limited bypassing length, the sliding deformation of support rope is still insufficient and as a result, the motion interference was commonly observed. Therefore, the system cannot be applied to intercept rockfall with high impact energy requiring high demand of large deformation. Gottardi et al. [4] carried out 5 full-scale impact tests of flexible rockfall barrier with impact energies of $500 \mathrm{~kJ}, 1000 \mathrm{~kJ}, 2000 \mathrm{~kJ}$, $3000 \mathrm{~kJ}$ and $5000 \mathrm{~kJ}$ respectively. For the $500 \mathrm{~kJ}$ and $1000 \mathrm{~kJ}$ systems, the control method for support rope sliding is the same as paper [5]; for the systems with design energy greater than 2000 $\mathrm{kJ}$, the transitional ropes are added to the system along the bypassing length, whose principle of sliding control was similar to that in the paper [10]. The difference is that the transitional rope can provide support for the ring net along the bypassing length, but motion interference may still occur. Obviously, the support ropes sliding on the post end smoothly restricts the impact deflection of the system and further affects the buffering performance of the system.

In reality, the causes for the development of large deflection of flexible rockfall barrier system are complicated. The limited number of full-scale tests under idealized conditions can only partially reflect the large deflection behavior of the system, further researches are still needed. Morton et al. [11] pointed out that the three-dimensional nonlinear analysis was the most effective complementary means. The technical difficulty of the three-dimensional nonlinear analysis of 
flexible rockfall barrier system mainly lies in the establishment of the mechanics model of the steel wire-ring net. At present, there are two representative methods. The first one is the continuous medium model, in which, the discrete ring net elements are modeled by continuous beam elements with a similar restoring force model $[12,13]$. However, this method commonly overestimates the stiffness of system and leads to a result with poor accuracy. The second method is a discrete beam element model, which uses the contact boundary to simulate the sliding contact between the rings $[4,15]$. This method produces more accurate results, but the modeling is complex with high computational cost. The simple and effective method for quick design of the system is urgently required. Besides, initial stress and initial shape also have great influence on the accurate prediction of the impact deflection, but force-finding and form-finding analysis of such cable-supported structures are major difficulties [21-23].

In this paper, based on the phenomena of impact deformation observed in full-scale impact tests, the working mechanism the flexible barrier system is analyzed. The major factors affecting the large deflection of the system are well considered, for example, the puncturing deformation of net, the stretching of the energy dissipator, the sliding of support rope and the rotation of support structure. Further, an analytical equation for prediction of the large deflection of flexible rockfall barrier system is proposed. The analytical solution accounts for deformation of each component such as the rotation of support structure, the sliding of the support rope and the puncturing deformation of net. Finally, the analytical solution method is verified by 17 puncturing tests with different specifications of ring nets and 3 groups of numerical simulations of whole system.

\section{LARGE DEFLECTION MECHANISM AND INFLUENCE FACTORS}

The deflection development of a flexible barrier system under $5000 \mathrm{~kJ}$ full-scale impact test was recorded by $1000 \mathrm{fps}$ (frames per second) high-speed camera and shown in Figure 4. From the observation of high-speed photos, the process of the deflection development of the system can be described as follows:

In stage I, the ring net slid along the support ropes and gathered in the mid-span of the support ropes near impact area, as shown in Figure $4 \mathrm{~b}$. Due to the small deflection characteristics, like bending and straightening, it was easy to find that the internal forces of the rings were small at this stage. From the statistical point of view, although the deflection in stage I accounted for about $30 \%$ of the total deflection, the energy dissipated was almost zero since all components were basically in elastic state and at the same time, the energy dissipators remained in the inactive stage.

In stage II, with the increasing of impact force, the internal forces of the support ropes increase dramatically. If the load transferred to the support rope reached a certain value, the energy dissipation device connected to the rope would be triggered and then maintained a steady tensile force, resulting in inelastic tensile deformation and dissipation of impact energy. When the tension of the support rope increased to a certain level fitting with the energy dissipation device, the ring net slid along ropes together forming a funnel-shaped deformation, as shown in Figures $4 \mathrm{c}$ and $4 \mathrm{~d}$. Along with the sliding of support rope, the funnel-shaped deformation of the system was more distinct, as shown in Figure 4e. Correspondingly, the vertical force of the steel post was rapidly 
increased due to the vertical force component in the support rope, and the energy dissipating device connected to anchor rope was activated with rotational behavior of steel post. The impact energy was largely dissipated and the deflection in this stage was up to $60-70 \%$ of the total deflection.

In stage III, the deflection of the steel-wire ring net in the contact area was continuously increased. The impact force on the system reached the maximum $F_{\text {max }}$. Finally, the steel-wire rings in the impact zone experienced clear diametrical and diagonal stretching behaviors. The rockfall gradually stopped moving, with a small amplitude of rebounding phenomenon.

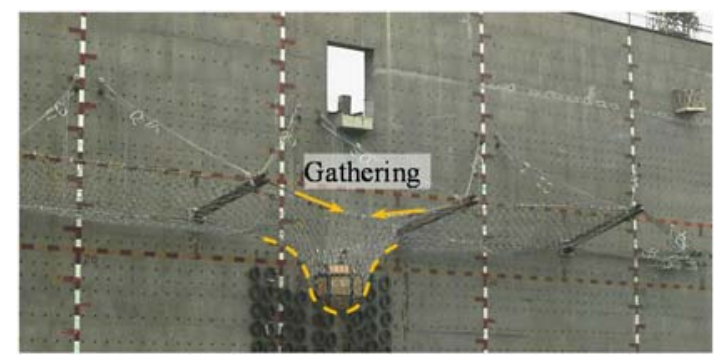

(a) Overall deflection of the system at $0.12 \mathrm{~s}$



(c) Overall deflection of the system at $0.26 \mathrm{~s}$

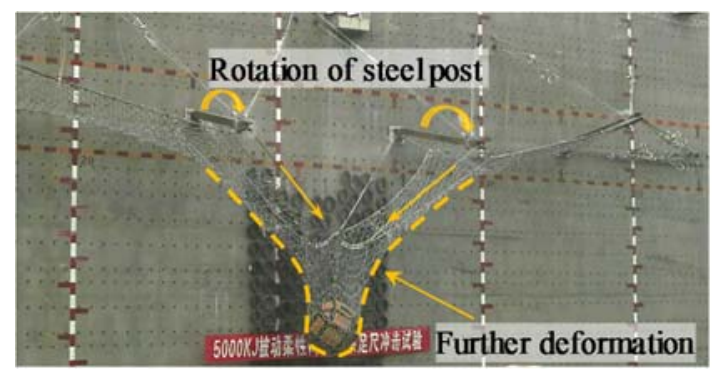

(e) Overall deflection of the system at $0.40 \mathrm{~s}$

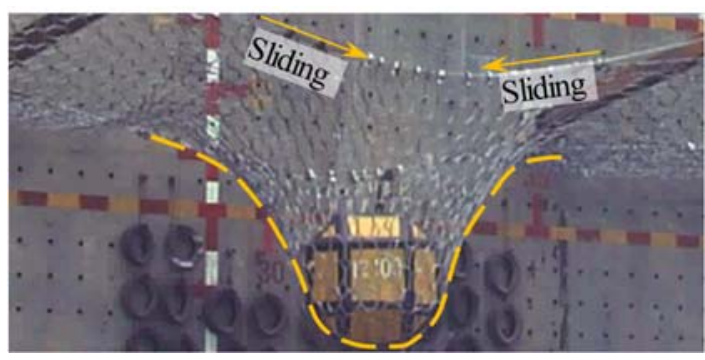

(b) Sliding of the ring net at $0.12 \mathrm{~s}$

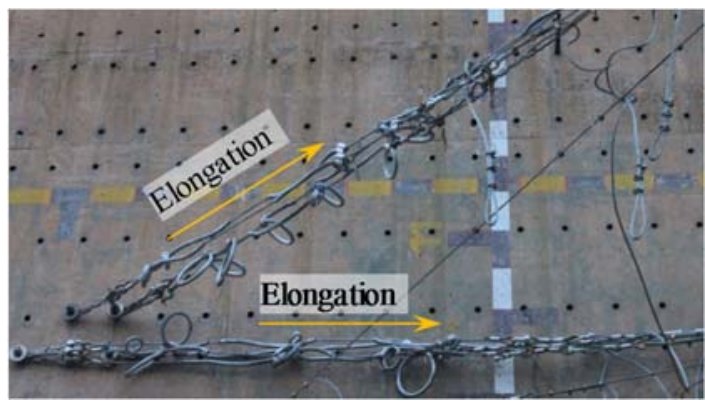

(d) Elongation of energy dissipating devices of support ropes at $0.26 \mathrm{~s}$

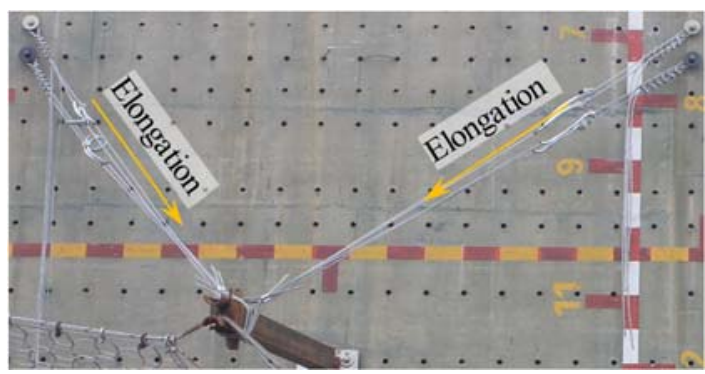

(f) Elongation of energy dissipating devices of upslope anchor ropes at $0.40 \mathrm{~s}$

Figure 4. Deflection Process of a Typical Flexible Barrier System

The studies $[2-4,8,10]$ showed that the impact time associated with the impact deflection $S_{\max }$ were extremely short, ranging from 0.2 to 0.5 second. The impact deflection of a typical flexible 
rockfall barrier was shown in Figure 5. The total deflection includes the deformation $\Delta_{1}$ of supporting structure, deflection $\Delta_{2}$ of support ropes, deflection $\Delta_{3}$ of ring net, installation sag $f_{\mathrm{r}}$ and $f_{\mathrm{n}}$ of rope and ring net respectively, and the deflection due to other components. The total deflection may be up to 10 meters [2-7, 15-20, 24-27] and therefore, the behavior of flexible rockfall barrier is a typical large deflection problem. In fact, many factors might affect the buffering behavior of the system, such as the large deflection of the mesh, the deformation of the energy dissipation device connected to ropes, the movement of the post end, the interference of the mesh and support structure. The clear understanding the large defection mechanism and the factors influencing system behavior forms a solid foundation to propose an analytical solution to predict the overall behavior of the flexible rockfall barriers.



Figure 5. Impact Behavior of Flexible Rockfall Barrier

\subsection{Deflection of Ring Net in Impact Zone}

Steel wire-ring nets, as the most important component in flexible rockfall barrier system, are subjected to impact load directly. According to European standard [1], ring nets are recommended to use when the protection energy level is from $2000 \mathrm{~kJ}$ to $8000 \mathrm{~kJ}$. A steel ring is made of high-strength steel wire woven in parallel or winding way. As shown in Figure 6a, a typical mesh element is composed of five steel rings, the inner one is loosely connected to four outer rings. When the net is loaded, this loose configuration allows the rings to change their positions, achieving an optimal configuration to resist the load. Thus, the deflection of rings is self-adapting. Actually, this self-adapting deflection is also applied to rings and support ropes due to similar loose connection. Morton et al. [11] studied the influence of the boundary effect between ring nets on the load transfer and deflection development. They pointed out that the loose connection is favorable to self-adapting deflection and can increase almost 3 times the nominal resistance of the meshes. Based on the field investigations and full-scale impact tests [2], it was found that the deflection characteristics in different regions of the flexible barrier are different due to the sliding between rings. Specifically, the rings in the impact region along the nominal height direction are diametrically stretched with significant elastoplastic deformation. Along the direction of the column spacing, the rings are generally in loose state with sliding-gather phenomenon. In the direct contact region, the rings are diagonally stretched, as shown in Figure 6b. Meanwhile, the remained rings in the non-impact region stay loosely due to lower stress level. The rings in different regions exhibit different behaviors due to various constraint conditions. This provides a basis for describing the 
deflection of the mesh in different regions.

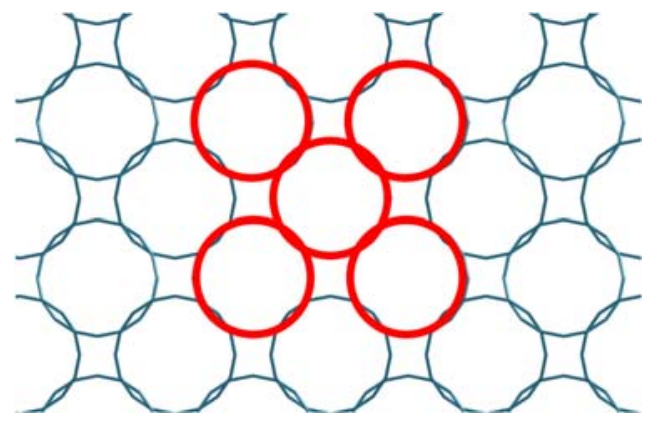

(a) Nesting forms of ring net



(b) Deflection of ring net in impact area

Figure 6. Ring Net of Flexible Rockfall Barrier

For simplicity, a ring chain unit as shown in Figure 7 is studied here. The unit is connected to two ropes vertically and several spring elements horizontally, representing the boundary conditions of support ropes and adjacent rings respectively. Under the tensile force $T$, the ring chain unit shows two typical behaviors, i.e. diametrical stretching and diagonal stretching, depending on the stiffness $k$ of the springs. Assuming that the initial length of the ring chain unit is $l_{0}$, and the final length is $l_{1}$ on diametrical stretching state or $l_{2}$ on diagonal stretching state after the deformation. It was reported from the reference [24] that, if the rings contact each other closely, $l_{1}$ will be significantly longer than $l_{0}$ while $l_{2}$ will be slightly smaller than $l_{0}$. However, the full-scale tests $[2,3]$ show that the ultimate tensile length of the mesh will increase, regardless of the stiffness $k$ of the springs, which is mainly due to the initial gaps between steel-wire rings. In order to simplify the calculation procedure, the authors introduce a coefficient $\varphi$ associated with tensile deformation as expressed in Eq. 2, which represents the combined effect of diagonal stretching, diametrical stretching and sliding of rings. Based on statistical regularities, $\varphi$ approximately equals to 0.55 when the surrounding rings are fixed or the rings are impacted by the block directly; $\varphi$ approximately equals to 0.9 when the surrounding rings are supported by steel ropes with sliding and gathering.

$\varphi=\frac{l_{i}}{l_{n i}}=\frac{l_{i}}{0.5 n_{\text {total }} \pi \mathrm{D}}(i=1,2)$

where $D$ is the nominal diameter of the mesh, $n$ is the number of rings connected end to end, and $l_{i}$ is the actual stretch length, and $l_{n i}$ is the ideally-stretching length.

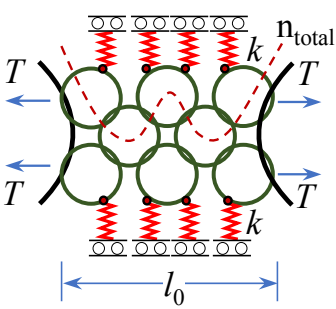

(a) Initial state

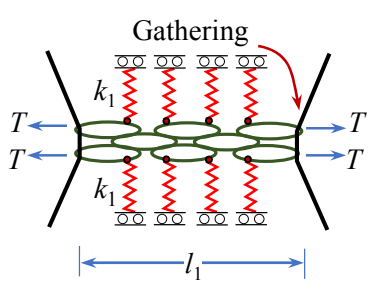

(b) Diametrical stretching

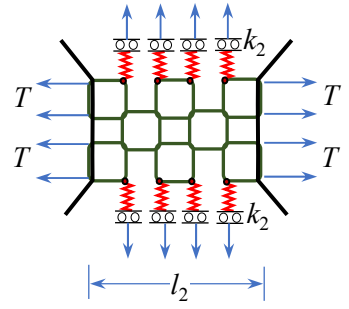

(c) Diagonal stretching

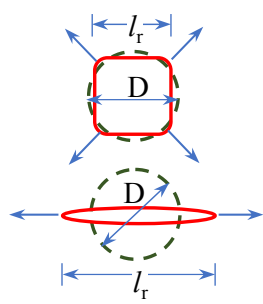

(d) Deflection mode 
Figure 7. Deflection of Meshes in Partition.

\subsection{Deflection of Energy Dissipating Device}

When the system is attacked by the rockfall, the impact force is transferred to the ring nets and then to the support ropes. Due to limited energy dissipation capacities provided by elastoplastic deformation of the ring net and steel ropes, the energy dissipating devices connected with steel ropes, as shown in Figure 8a, are necessary to absorb impact energy and protect the ropes and ring nets. Once the tension force in the rope reaches a certain value, the energy dissipating device will start to work, as shown in Figure 8b, leading to the sliding of the connected ropes. The energy dissipating devices attached to steel ropes can consume $60-80 \%$ of total impact energy on the system [6,7]. The research [25] shows that no matter frictional, yielding and hybrid energy dissipating devices, the restoring force characteristics of them are similar, as shown in Figure 8b. The effect of energy dissipating device on the impact deformation of the system is directly related to the mechanical behavior of the connected rope. The key parameters of energy dissipating device include the ultimate elongation $\delta_{\max }$, mobilizing force $P_{\mathrm{a}}$ and working force $P_{\mathrm{s}}$. The elongation $\delta_{\max }$ determines the sliding distance while $P_{\mathrm{a}}$ and $P_{\mathrm{s}}$ determine the tensile force of connected rope. It should be emphasized that as the energy dissipating devices are directly connected to the ropes, the buffer performance of the system can be ensured only if they are adaptive each other. The energy absorbed by an energy dissipator can be expressed as

$$
E_{d}=\int_{0}^{\delta_{\max }} P(\delta) d \delta
$$

where $E_{\mathrm{d}}, P(\delta), \delta$ are the energy dissipated, the working force and the elongation of the energy dissipating device respectively.

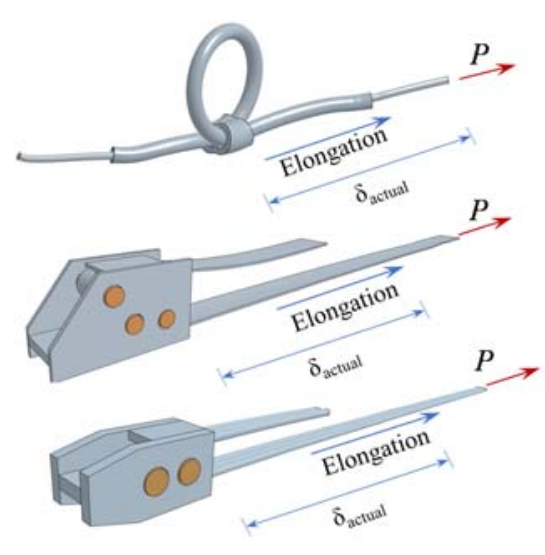

(a) Typical energy dissipating device



(b) Working principle and P-D characteristic of energy dissipating device

Figure 8. Energy Dissipating Device in Flexible Rockfall Barrier System

For practical use with consideration of cost efficiency, the required minimum elongation of the 
energy dissipating device can be determined by the energy dissipating demand of the connected ropes in different locations, as shown in Eq.4.

$$
\begin{aligned}
& \delta_{\text {min }}^{\mathrm{a}}=\frac{E_{\mathrm{a}}}{0.5\left(P_{\mathrm{a}}+P_{\mathrm{s}}\right)} \\
& \delta_{\text {min }}^{\mathrm{s}}=\frac{E_{\mathrm{s}}}{0.5\left(P_{\mathrm{a}}+P_{\mathrm{s}}\right)} \\
& \mu_{\mathrm{a}}=\frac{\delta_{\text {actual }}^{\mathrm{a}}}{\delta_{\text {min }}^{\mathrm{a}}} \\
& \mu_{\mathrm{s}}=\frac{\delta_{\text {actual }}^{\mathrm{s}}}{\delta_{\text {min }}^{\mathrm{s}}}
\end{aligned}
$$

where $E_{\mathrm{a}}$ and $E_{\mathrm{s}}, \delta_{\text {actual }}^{\mathrm{a}}$ and $\delta_{\text {actual, }}^{\mathrm{s}}, \mu_{\mathrm{a}}$ and $\mu_{\mathrm{s}}$ are the energy dissipating demand, the actual elongation and the efficiency factor of energy dissipating device connected to upslope anchor ropes and support ropes respectively.

Previous researches [6,7] show that, energy dissipation ratios of energy dissipating devices connected to different ropes over whole system present a specific statistical characteristic, as shown in Table 1. When designing a flexible rockfall barrier, the number and configuration of energy dissipating devices connected to different types of ropes can be determined, provided that the performance parameters of a single energy dissipating device are known.

Table 1. Energy Dissipation Ratio

\begin{tabular}{cccc}
\hline Composition & Upslope anchor ropes & Support ropes & Others \\
\hline Energy dissipation ratio & 0.2 & 0.6 & 0.2 \\
\hline
\end{tabular}

\subsection{Sliding of Support Rope}

The support ropes usually are passed through the ends of steel posts with initial state of suspension, as shown in Figure 9a, and hang the ring nets as shown in Figure 9b. When the ring nets transfer the impact force to the support ropes, the energy dissipating devices connected to these ropes will be mobilized and then dissipate energy via plastic deformation. The mobilization of the energy dissipating device depends on the tension of the associated rope, while the total tensile deformation depends on the available sliding distance of the associated rope. To ensure smooth sliding of support ropes upon the steel posts, movement interferences between different components must be avoided via proper configuration of the whole system. Generally, the dissipating devices usually are set at the anchorages of the ropes, as shown in Figure 9c. Meanwhile, it should be pointed out that the ropes should not wrap with rings to ensure sufficient sliding distance. 


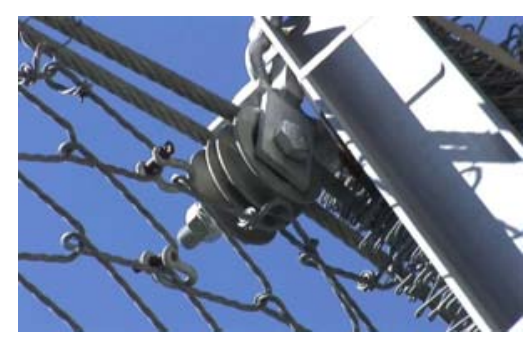

(a) Connection between support rope and steel post

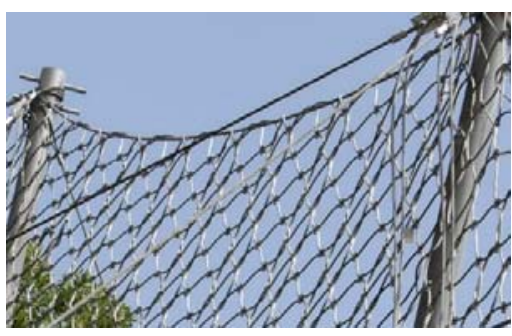

(b) Connection between support rope and ring net

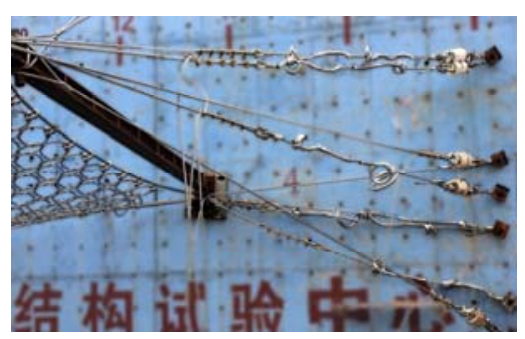

(c) Location of energy dissipating devices in the support rope

Figure 9. Setting of Support Rope

At the end of steel post, the support rope will slide upward through the base connection. The mesh or transitional rope will move reversely during the impact of rockfalls, which will alleviate the movement interference problem between the components nearby the post, as shown in Figure 10a. If the support rope or mesh has sufficient sliding distance at the end of the post, the sliding movement can be regarded as a gradual process and therefore, will be beneficial for the improvement of the structural buffering performance. In the mid-span of the support rope, the ring net and the rope are connected by shackles and thereby, the axial direction of the rope is free to slide, as shown in Figure 10b. In the normal direction, the ring net and the rope work together such that the internal force of the rope is self-adaptive and tend to be uniform along the length in the impact zone. When the impact load is longitudinally transferred to the non-impact zones, the internal force of the rope will be rapidly reduced with the increasing distance to the rockfall impact zone. As the actual rockfall impact area is unknown, the end ring nets are often connected to the lateral support ropes with energy dissipating devices to minimize the potential damage, in case the rockfalls hit the end spans, as shown in Figure 10c. The energy dissipating device on the lateral rope will be functioned when the force transferred to the lateral support rope is large to activate it, protecting the lateral post and adjacent structural components.



(a) Sliding of support rope at post end



(b) Sliding of support rope at mid-span



(c) Sliding of support rope at end span

Figure 10. Sliding of Support Rope 


\subsection{Deflection of Support Structure}

The support structure is the key component to maintain the integrity of the flexible rockfall barrier. In practice, the form of the support structure should be determined by the actual terrain condition. Under the impact of falling rock, the support structure may undergo elastoplastic deformation, which is undesirable because the support structure has limited energy dissipating capacity compared to the whole system. Also, the main duty of the support structure is to support the steel ropes and ring nets. To reduce the direct impact load on the support structure, the structural forms as shown in Figure 11 are widely used. Generally, the support structure is composed of a rotatable steel post and upslope anchor ropes with energy dissipating devices. The rotation of steel post caused by the elongation of energy dissipating device is significant, leading to the rigid body movement of ring net. The structural form in Figure 11c is most welcomed due to simple configuration and clear deflection. This form is mainly governed by the elongation of the energy dissipating devices connected to upslope anchor ropes, which can be accurately calculated by the geometric method. It should be pointed out that the deflection contribution of the support structure to the total deflection of the system is negligible if it is well designed with careful consideration of structural stability.

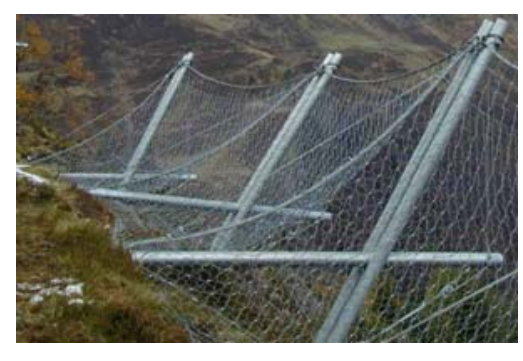

(a) Type 1

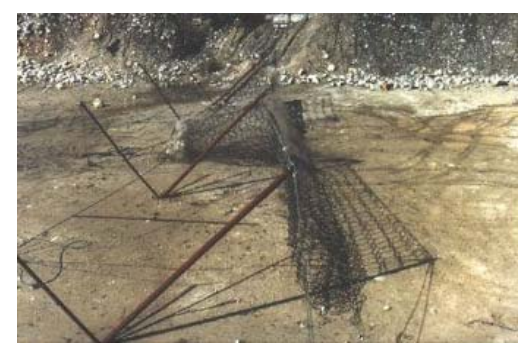

(b) Type 2

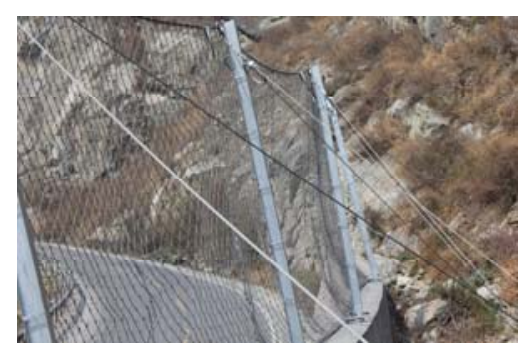

(c) Type 3

Figure 11. Typical Configurations of Support Structure

\section{ANALYTICAL SOLUTION OF LARGE DEFLECTION}

At present, the prediction of impact response of flexible rockfall barrier is mainly relied on numerical simulation method $[2,4,6,8,10]$. However, according to the observation from full-scale tests $[3,4,5]$, the deflections of flexible rockfall barriers show typical characteristics and statistical trend. For this reason, an analytical method based on space geometry is proposed in this paper to approximately predict the deflection of a flexible barrier subjected a rockfall impact, as shown in Eq. 5.

$$
\Delta_{1 \mathrm{a}}+\Delta_{2 \mathrm{~s}}+\Delta_{3 \mathrm{n}} \approx S_{\max }
$$

in which, $\Delta_{1 \mathrm{a}}$ is the deflection of the support structure, $\Delta_{2 \mathrm{~s}}$ is the sliding movement of support ropes, and $\Delta_{3 \mathrm{n}}$ is the deflection of ring net. The detailed calculation of each component will be presented in the followings. The deflection from Eq. 5 can provide a simple and quick method for the selection 
and design of flexible rockfall barrier according to the work-energy principle.

\subsection{Deflection of Support Structure}

As mentioned above, if the stiffness of support structure is large enough, the natural deflection associated with elastoplasticity deformation could be neglected while the rigid body movement associated with rotation of steel post caused by elongation of energy dissipating device connected to upslope anchor ropes should be considered in the prediction of total deflection of a flexible barrier system, as shown in Figure 11c. The spatial positions of a steel post before and after impact are shown in Figure 12. The deflection $\Delta_{1}$ of the steel post head is the projective height difference in $\mathrm{XZ}$ plane before and after the impact, which can be calculated from Eq. 6. The required parameters are obtained on the basis of experimental tests and the assumptions as follows: (1) the configuration of the system is symmetrical; (2) the axial compression deformation of steel post and the sag of upslope anchor rope are ignored; (3) the minimum elongation of energy dissipating device $\delta_{\min }^{i}$ is determined by Eq. 4a; (4) the stretching efficiency of energy dissipating device is defined in Eq. $4 \mathrm{~b}$, in which $\mu_{1}$ is taken as 1.0 while $\mu_{2}$ is related to the design energy level $E$. If $E$ is not greater than $2000 \mathrm{~kJ}, \mu_{2}$ is taken as 0.2 ; if $E$ is not less than $3000 \mathrm{~kJ}, \mu_{2}$ is taken as 0.75 . As there is no product with design energy between $2000 \mathrm{~kJ}$ and $3000 \mathrm{~kJ}$ in market, $\mu_{2}$ should be further studied if a new system is developed in this range. After the impact, the post was deformed rotationally in both the vertical and horizontal directions at the same time. Because of the different forces on the energy dissipating devices at two sides of the steel post, the elongations of the connected upslope anchor ropes are unequal. The length of upslope anchor rope 1 and 2 change from $L_{0}$ to $L_{1}$, while the length of upslope anchor rope 3 and 4 change from $L_{0}$ to $L_{2}$. According to the triangular similarity relation, the deflection in the middle of the steel post $\Delta_{1 \text { a }}$ equals to $0.5 \Delta_{1}$ as

$$
\begin{aligned}
& A_{\mathrm{a}}=0.54=0.5(H-h)=0.5\left[L_{\mathrm{AB}^{\prime}} \cdot \cos \alpha-\left(H_{\mathrm{d}}-H_{\mathrm{p}} \sin \beta\right)\right] \\
& \cos \alpha=\frac{H_{\mathrm{d}}^{2}+L_{\mathrm{AB}^{\prime}}{ }^{2}-H_{\mathrm{p}}}{2 H_{\mathrm{d}} L_{\mathrm{AB}^{\prime}}} \\
& L_{\mathrm{AB}}=\sqrt{\left(\frac{U_{\mathrm{h}}}{2}\right)^{2}+L_{2}^{2}-2 \cdot \frac{U_{\mathrm{h}}}{2} \cdot L_{2} \cdot \cos \theta}=\sqrt{\left(\frac{U_{\mathrm{h}}}{2}\right)^{2}+\left(L_{0}+\mu_{2} \delta_{1}\right)^{2}-2 \cdot \frac{U_{h}}{2} \cdot\left(L_{0}+\mu_{2} \delta_{1}\right) \cdot \cos \theta} \\
& \cos \theta=\frac{L_{2}{ }^{2}+U_{\mathrm{h}}^{2}-L_{1}^{2}}{2 L_{2} U_{\mathrm{h}}}=\frac{\left(L_{0}+\mu_{2} \delta_{1}\right)^{2}+U_{\mathrm{h}}{ }^{2}-\left(L_{0}+\mu_{1} \delta_{1}\right)^{2}}{2\left(L_{0}+\mu_{2} \delta_{1}\right) U_{\mathrm{h}}}
\end{aligned}
$$

where $H_{\mathrm{d}}$ is the distance from the anchorage of the upslope anchor rope to the foundation of the steel post in $\mathrm{Z}$ direction, $H_{\mathrm{p}}$ is the length of the steel post, $U_{h}$ is the distance between the anchorages of the adjacent upslope anchor ropes, $\beta$ is the initial angle between post and XY plane. These parameters can be determined in the stage of preliminary design, the projective angle $\alpha$ is the angle between the auxiliary line $L_{\mathrm{AB}^{\prime}}$ and the $\mathrm{XZ}$ plane, which can be determined according to the trigonometric relationship. 


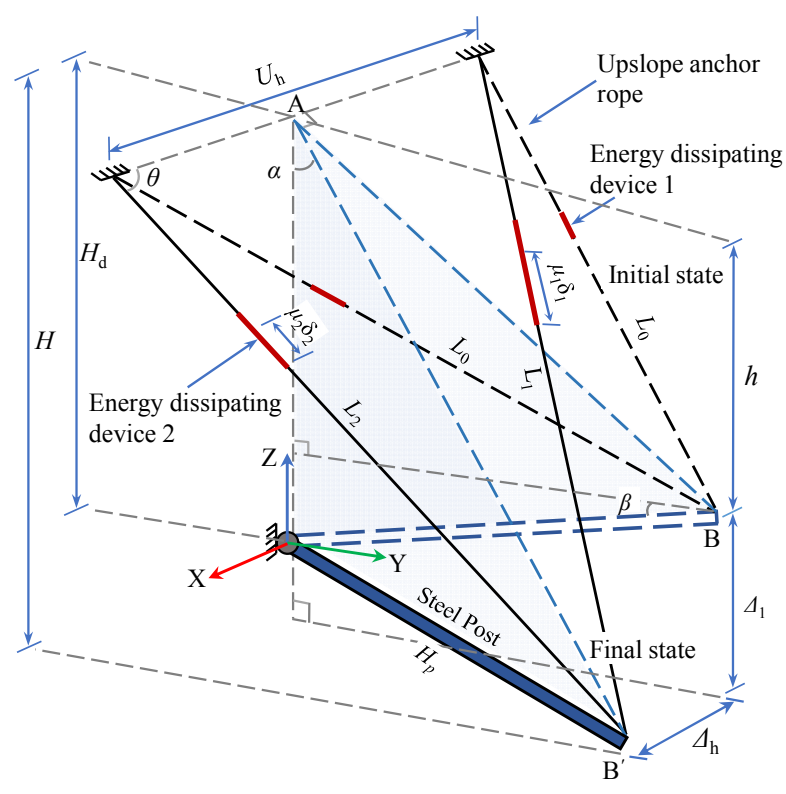

(a) Spatial relations



(b)XY plane

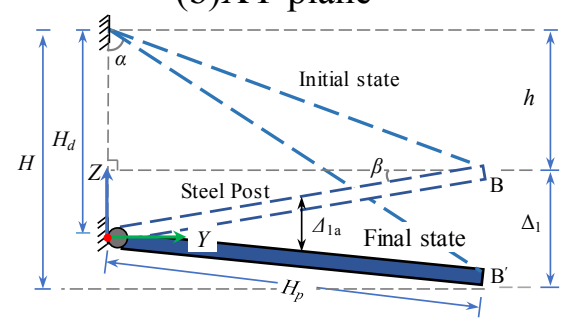

(c)YZ plane

Figure 12. Deflection $\Delta_{1 \mathrm{a}}$ of Support Structure

\subsection{Sliding Movement of Support Rope}

Owing to the elongation of the energy dissipating device, the support rope on the impact span will deform in a tilted V-shape, as shown in Figure 13a. The projective height of the V-shaped deflection in $\mathrm{XZ}$ plane is the component $\Delta_{2}$ of support rope. The value of $\Delta_{2}$ is the elevation difference between the end of the steel post and the bottom of the support rope in $Z$ direction. After deducting the initial sag of the support rope $f_{\mathrm{r}}$, the vertical deflection $\Delta_{2 \mathrm{~s}}$ due to the sliding of support rope can be obtained from Eq. 7 as

$$
\begin{aligned}
& \Delta_{2 \mathrm{~s}}=\Delta_{2}-f_{\mathrm{r}} \approx \sqrt{\left(\frac{L_{\mathrm{d}}+\mu_{3 \mathrm{~L}} \delta_{3 \mathrm{~L}}+\mu_{3 \mathrm{R}} \delta_{3 \mathrm{R}}-0.5 w_{\mathrm{s}}}{2}\right)^{2}-\left[\left(L_{\mathrm{hd}}\right)^{2}+\left(0.25 H_{\mathrm{p}}\right)^{2}\right]}-f_{\mathrm{r}} \\
& L_{\mathrm{hd}} \approx \frac{L_{\mathrm{d}}-0.5 w_{\mathrm{s}}}{2}
\end{aligned}
$$

where $L_{\mathrm{d}}$ is the steel post spacing, $\mu_{3 \mathrm{~L}}$ and $\mu_{3 \mathrm{R}}, \delta_{3 \mathrm{~L}}$ and $\delta_{3 \mathrm{R}}$ represent the stretching efficiency and the designed elongation of energy dissipating devices connected to support ropes at the left and right respectively. The statistics analysis based on full-scale tests and numerical simulations show that both $\mu_{3 \mathrm{~L}}$ and $\mu_{3 \mathrm{R}}$ are close to 1.0 .

The experimental tests are also shown that $f_{\mathrm{r}}$ is around $4 \%$ of the spacing between steel posts; the bottom of V-shaped deflection can be simplified to a straight segment; and the width of straight segment is around 0.5 times of the diameter of rockfall $w_{\text {s, }}$ as shown in Figure 13b. Considering the 
European standard with experimental statistics, the remaining width of the support rope in XY plane $h_{\mathrm{R}}$ is $0.5 H_{\mathrm{p}}$ [1-5], which means that the total deflection of support ropes 1 and 2 in $\mathrm{Y}$ direction is $0.25 H_{\mathrm{p}}$, as shown in Figure $13(\mathrm{~b}, \mathrm{c})$.

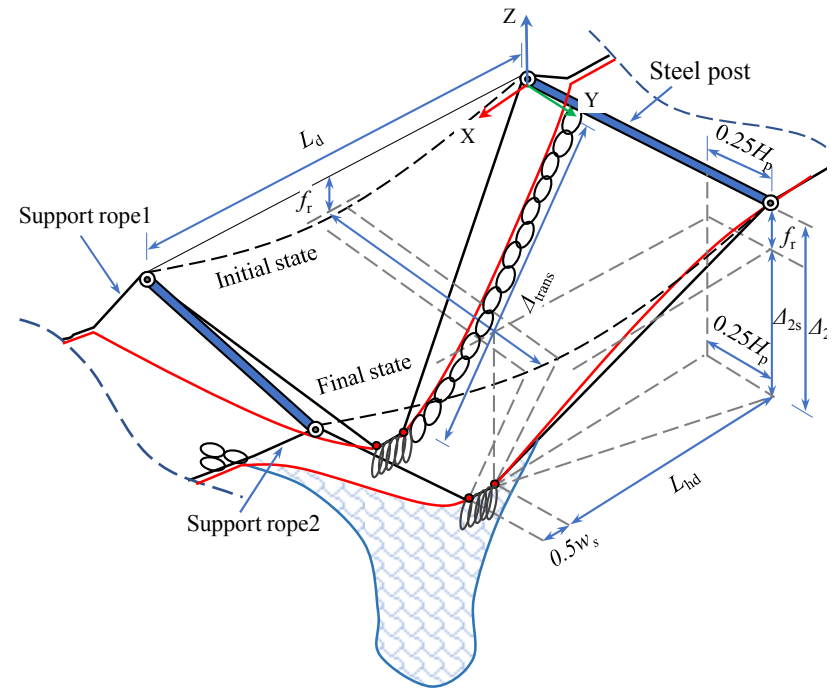

(a) Spatial relations

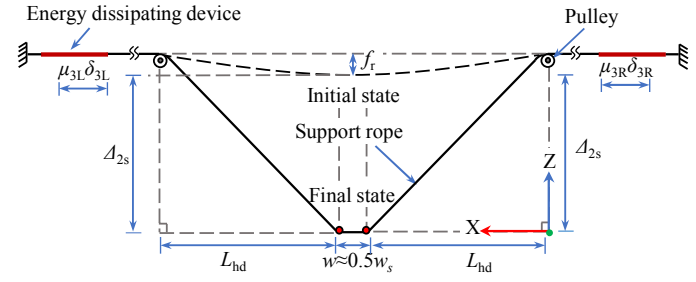

(b) XZ plane

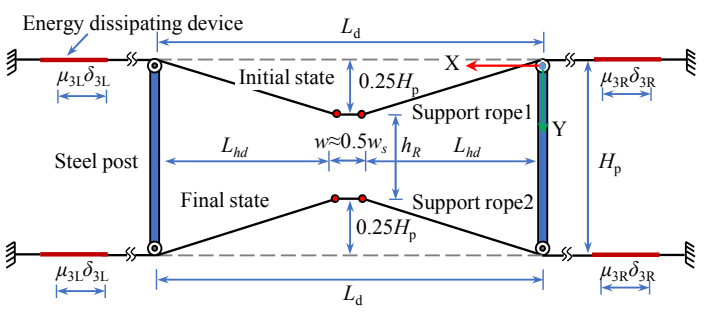

(c) XY plane

Figure 13. Sliding Movement $\Delta$ 2s of Support Rope

The sliding of support rope is restricted by the limited stretching length of steel-wire rings along the bypassing length $\Delta_{\text {trans, }}$ as shown in Figure 13. The length $\Delta_{\text {trans }}$ can be computed from the geometric relationship, which is the product of the maximum diameter stretching deflection of a single ring and the number of diametrical stretching rings on transitional rope $n_{\mathrm{t}}$. However, the insufficient development of the diametrical stretching deformation of the steel-wire rings cannot be ignored, and therefore a reduction factor $\varphi$ defined in Eq. 2 should be adopted. In summary, $\Delta$ trans can be calculated as

$$
\Delta_{\text {trans }}=n_{\mathrm{t}}\left(\frac{\pi D}{2}-D\right) \varphi
$$

where $D$ is the diameter of the ring, $n \mathrm{t}$ is the number of diametrical stretching rings on transitional rope. According to the statistics of full-scale tests and numerical simulations, $\varphi$ is close to 0.8 .

From the above, the actual allowable elongation $\left[\delta_{e s}\right]$ of energy dissipating device on support rope can be estimated from Eq. 9.

$$
\left[\delta_{e s}\right]=\left[\min \left(\delta_{3}, 4_{\text {rans }}\right)+\delta_{3}\right] / 2
$$

where $\delta_{3}$ is the designed elongation of energy dissipating devices connected to support ropes. 


\subsection{Puncturing Deflection of Ring Net}

As shown in Figure 14, after subjected to the impact of rockfall, the ring net will present an clear funnel-shape. The total deflection of ring net due to sliding, diametrical stretching and diagonal stretching, can be calculated by the elevation difference between the bottom of the funnel-shaped ring net and the bottom of the $\mathrm{V}$-shaped support rope $\Delta_{3}$. After deducting the initial sag $f_{\mathrm{n}}$, the puncturing deflection $\Delta 3 \mathrm{n}$ of ring net can be obtained. Because the nominal height of the flexible rockfall barrier is less than the longitudinal length, the internal forces as well as deflection are mainly depended on the nominal height direction, which is similar to the one-way slab. The experimental tests show that in the nominal height direction, the steel-wire rings deform as diametrical and diagonal stretching in noncontact and impact areas respectively, as shown in Figure 14a. The relaxation of longitudinal steel-wire rings is worse than that of transverse steel-wire rings, as shown in Figure 14b. For this reason, the internal forces of longitudinal steel-wire rings are also smaller.

From the above, an analytic model, as shown in Figure 14b, can be established according to the deformed shape of ring net to estimate the puncturing deflection $\Delta 3 \mathrm{n}$ as

$$
\begin{aligned}
& \Delta_{3 \mathrm{n}} \approx \Delta_{3}-f_{\mathrm{n}}=\sqrt{\left(\frac{l_{i}-w_{\mathrm{s}}}{2}\right)^{2}-\left(\frac{h_{\mathrm{R}}-w_{\mathrm{s}}}{2}\right)^{2}}+h_{\mathrm{c}}-f_{\mathrm{n}} \\
& l_{i}=l_{i 0}+\left(n_{\text {total }}-n_{\text {contact }}\right)\left(\frac{\pi D}{2}-D\right) \varphi \\
& n_{\text {diagonal }}=I N T\left(\frac{4 w_{\mathrm{s}}}{\pi D}\right)+1
\end{aligned}
$$

where, $l_{i 0}$ is the initial nominal height of the ring net, which approximately equals to $H_{\mathrm{p}}$; $l_{i}$ is the total stretching deformation in nominal height direction in non-contact area; $h_{\mathrm{R}}$ is the residual interception height; $n_{\text {contact }}$ is the number of steel-wire rings impacted by the rockfall; $h_{\mathrm{c}}$ is the local puncturing depth in the contact area. These parameters can be determined in the preliminary design stage.

It is noted that the puncturing deflection of the ring net mainly occurs in the impacting span. Thus, the deflection relies on the gaps between rings in nominal height direction, the number $n_{\text {total }}$ of steel-wire rings continuously connected in nominal height direction, the deflection development coefficient $\varphi$ in the contact and non-contact areas as defined by Eq. 2. The mentioned parameters should be determined by experimental tests.

Assuming that $\Delta 3 \mathrm{n}$ mainly depends on the sliding movement between steel-wire rings in nominal height direction and the diametrical stretching deflection of the ring net in non-contact area. According to the statistics of tests, the parameter $\varphi$ is 0.55 and 0.9 for contact area and non-contact area respectively. The initial gap $f_{\mathrm{n}}$ of the ring net is approximately equal to $15 \%$ of $H_{\mathrm{p}}$. 


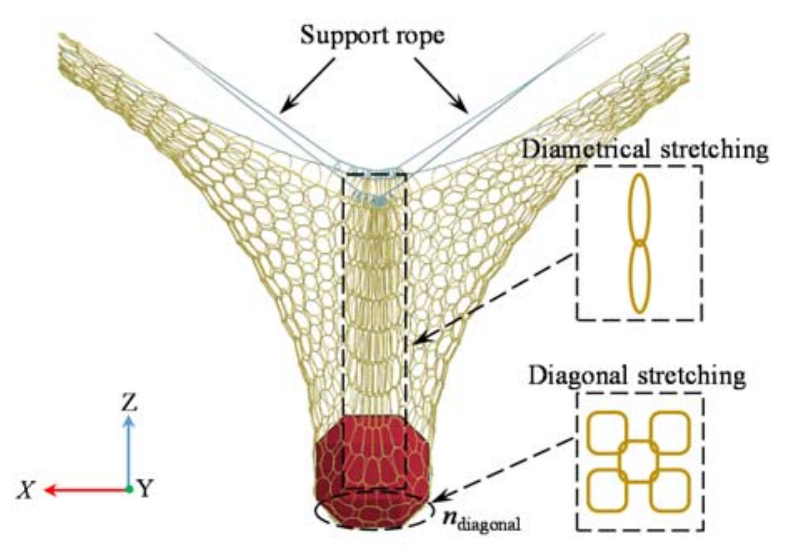

(a) XZ plane



(b) YZ plane

Figure 14. Puncturing Deflection $\Delta_{3 \mathrm{n}}$ of Ring Net

\section{VERIFICATION EXAMPLES}

From the mentioned above, the calculation of $\Delta_{1 \mathrm{a}}$ is based on a relatively accurate spatial geometrical relationship, which mainly relies on the elongation of the energy dissipating device connected to the upslope anchor rope. The calculation of $\Delta_{2 \mathrm{~s}}$ is based on several assumptions and therefore the analytical solution is approximate. The deflection $\Delta_{3 \mathrm{n}}$ is mainly affected by the stretching behaviors of the steel rings. Particularly, the sliding and gathering movement of the steel-wire ring net in the impact zone along the longitudinal direction of the support rope has a significant influence on the development of the diametrical stretching behavior of the ring net. The gathering behavior observed from full-scale tests is the dominant one [2, 3]. In addition, $\Delta 3 \mathrm{n}$ is the relative deflection of the steel-wire ring net controlled by limiting factors. The accuracy of $\Delta 3 \mathrm{n}$ can be improved clearly by increasing the accuracy of coefficient $\varphi$. The proposed analytical solution will be validated in this section and the accuracy will be discussed.

\subsection{Puncturing Test of Ring Net}

Totally 17 ring nets made of different sizes of steel rings were tested in this paper. The specimens in puncturing test were $2800 \mathrm{~mm} \times 2800 \mathrm{~mm}$ with the steel rings of $\mathrm{R} 5 / 3 / 300, \mathrm{R} 7 / 3 / 300, \mathrm{R} 9 / 3 / 300$, $\mathrm{R} 12 / 3 / 300, \mathrm{R} 16 / 3 / 300$ and $\mathrm{R} 19 / 3 / 300$. The steel rings are denoted as $\mathrm{R} a / b / c$, where $a$ is the number of the windings of steel wire, $b$ is the diameter of steel wire and $c$ is the diameter of single steel-wire ring. For each kind of steel ring, there were three ring nets except R19/3/300, which only has two specimens. For each specimen, its edges were connected to a reaction frame by shackles. Each ring net was punctured vertically by the displacement loading with a speed of $2 \mathrm{~mm} / \mathrm{s}$ till the fracture of the net, seen in Figure 15.

The force-displacement curves of the ring nets with different specifications of rings obtained from test were plotted in Figure 16. The test results showed that with the increase of the winding numbers, the puncturing deflection of the net will be decreased with small variation. The total deflection of each specimen was around $1000 \mathrm{~mm}$. 




(a) Initial state

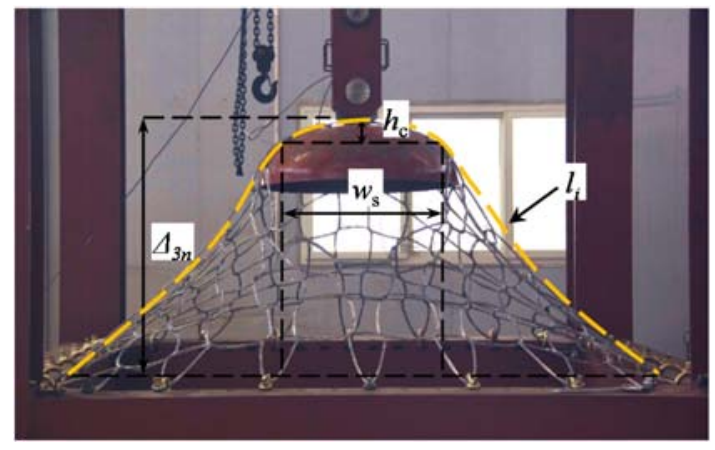

(b) Broken state

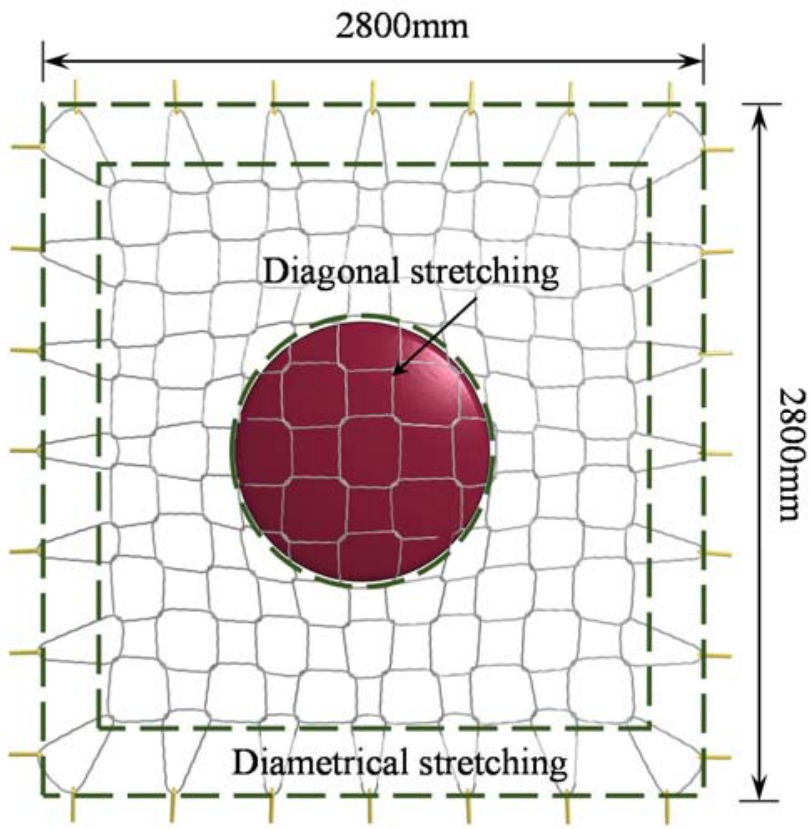

(c) Deformation of ring net

Figure 15. Puncturing Test of Ring Net

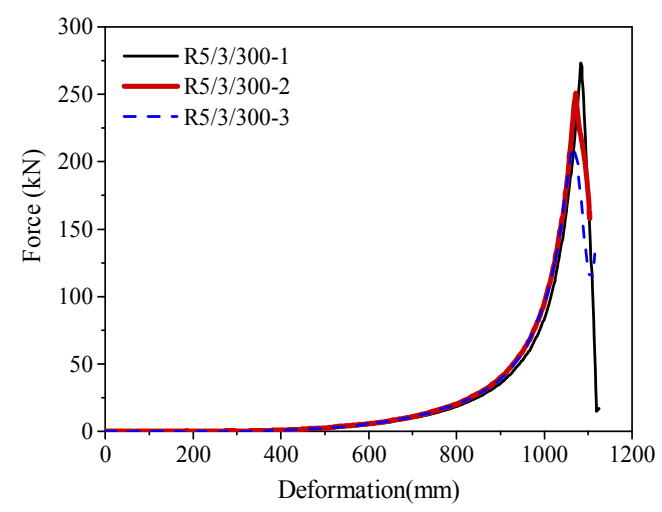

(a) $\mathrm{R} 5 / 3 / 300$

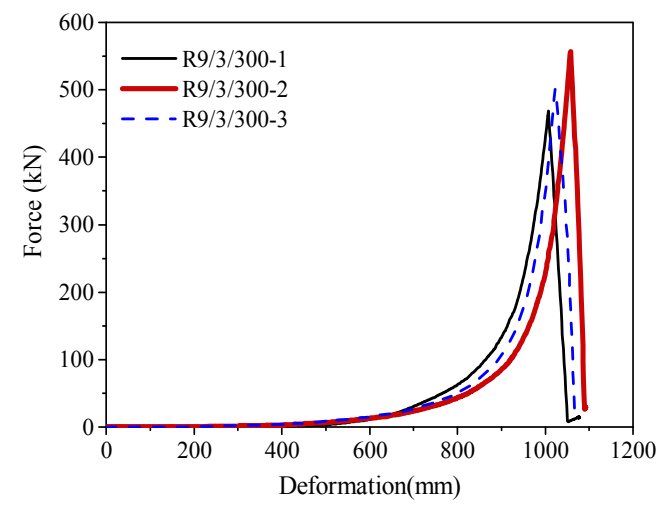

(c) $\mathrm{R} 9 / 3 / 300$



(b) $R 7 / 3 / 300$

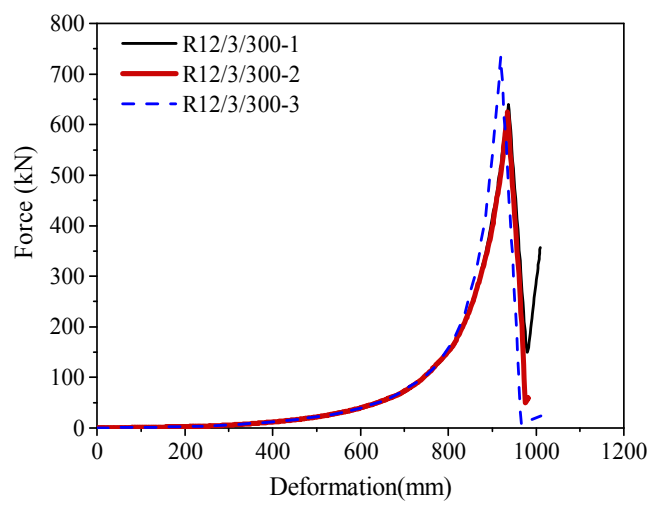

(d) R12/3/300 


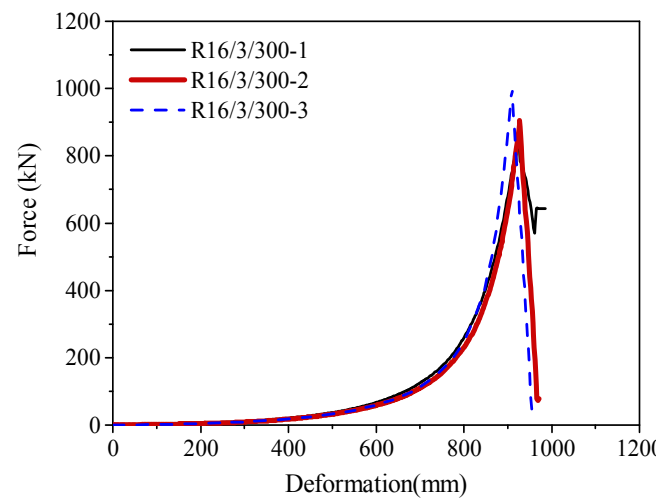

(e) R16/3/300



(f) R19/3/300

Figure 16. Force-Displacement Curves of Ring Nets

The average puncturing deflections of these nets with different specifications of rings are shown in Table 2. The actual stretching deflection $l_{i}$ is shown in Figure $15 \mathrm{~b}$ while $l_{\mathrm{n}}$ is the ideally-stretching length, as defined in Eq. 2. The coefficient $\varphi$ is also defined in Eq. 2. The initial nominal height $l_{i 0}$ of the ring net is $2.8 \mathrm{~m}$. The diameter $w_{s}$ of the press is $1 \mathrm{~m}$, and $h_{\mathrm{c}}$ is $0.11 \mathrm{~m}$. The initial sags $f_{\mathrm{n}}$ of these nets were approximately zero. The parameters $n_{\text {total }}$ and $n_{\text {contact }}$ are taken as 13 and 5 respectively. As the edge of the net was connected to a reaction frame by shackles, $h_{R}$ is taken as $2.80 \mathrm{~m}$ in the calculation of $\Delta_{3 \mathrm{n}}$.

Accordingly, the puncturing deflection of the net was $1.02 \mathrm{~m}$ calculated from Eq. 10 with $\varphi$ taken as 0.55 . The maximum difference compared with the test results was $7.4 \%$. The value of $\varphi$ from tests was ranged from 0.56 and 0.57 , and therefore the maximum difference between the statistic value of 0.55 was $3.5 \%$.

Table 2 Puncturing Deflection and Coefficients from Test

\begin{tabular}{ccccccc}
\hline Deflection & $\mathrm{R} 5 / 3 / 300$ & $\mathrm{R} 7 / 3 / 300$ & $\mathrm{R} 9 / 3 / 300$ & $\mathrm{R} 12 / 3 / 300$ & $\mathrm{R} 16 / 3 / 300$ & $\mathrm{R} 19 / 3 / 300$ \\
\hline$\Delta_{3 n}(\mathrm{~m})$ & 1.07 & 1.04 & 1.03 & 0.98 & 0.96 & 0.95 \\
$l_{i}(\mathrm{~m})$ & 3.48 & 3.43 & 3.43 & 3.46 & 3.47 & 3.49 \\
$l_{\mathrm{n}}(\mathrm{m})$ & 6.13 & 6.13 & 6.13 & 6.13 & 6.13 & 6.13 \\
$\varphi$ & 0.57 & 0.56 & 0.56 & 0.56 & 0.57 & 0.57 \\
\hline
\end{tabular}

\subsection{Numerical Simulation of Flexible Barrier Systems}

\subsubsection{Introduction of Three Flexible Barriers}

Three flexible barrier systems with design energy capacities of $2000 \mathrm{~kJ}, 3500 \mathrm{~kJ}$ and $5000 \mathrm{~kJ}$ are studied here. The layouts of the models are same and shown in Figure 17. For each system, it is mainly composed of steel posts, steel-wire ring nets, upper support ropes, lower support ropes, 
lateral support ropes, upslope anchor ropes, lateral anchor ropes, energy dissipating devices and connected components. The energy dissipating devices are located at the outside of end spans when connecting to support ropes and placed at the anchorage points when connecting to upslope anchor ropes. The configuration and the combination of the energy dissipating devices were determined according to the design impact energy, as given in Table 3. All models have three typical spans. The parameters such as $L_{d}, H_{\mathrm{p}}, H_{\mathrm{u}}, H_{\mathrm{d}}, \beta$ and $n_{\mathrm{t}}$ defined in previous sections are listed in Table 4 . The steel ropes were made of 6x19S+IWR with tensile strength of $1770 \mathrm{MPa}$. The ring nets were woven by the high-strength steel-wire, whose diameter was $3 \mathrm{~mm}$ and the tensile strength was $1770 \mathrm{MPa}$ [31]. The specifications of the components were detailed in Table 5.

Table 3. Configuration of Energy Dissipation Devices

\begin{tabular}{|c|c|c|c|c|c|c|c|c|}
\hline \multirow[b]{3}{*}{ Model } & \multicolumn{8}{|c|}{ Energy dissipating device } \\
\hline & \multicolumn{2}{|c|}{ Upper support rope } & \multicolumn{2}{|c|}{ Lower support rope } & \multicolumn{2}{|c|}{ Anchor rope } & \multicolumn{2}{|c|}{ Lateral support rope* } \\
\hline & $\begin{array}{c}P_{\mathrm{a}} / P_{\mathrm{s}} \\
(\mathrm{kN})\end{array}$ & $\begin{array}{c}\delta_{3 \mathrm{~L}} / \delta_{3 \mathrm{R}} \\
(\mathrm{m})\end{array}$ & $\begin{array}{c}P_{\mathrm{a}} / P_{\mathrm{s}} \\
(\mathrm{kN})\end{array}$ & $\begin{array}{c}\delta_{3 \mathrm{~L}} / \delta_{3 \mathrm{R}} \\
(\mathrm{m})\end{array}$ & $\begin{array}{c}P_{\mathrm{a}} / P_{\mathrm{s}} \\
(\mathrm{kN})\end{array}$ & $\begin{array}{c}\delta_{1} / \delta_{2} \\
(\mathrm{~m})\end{array}$ & $\begin{array}{c}P_{\mathrm{a}} / P_{\mathrm{s}} \\
(\mathrm{kN})\end{array}$ & $\begin{array}{c}\delta_{4} \\
(\mathrm{~m})\end{array}$ \\
\hline $2000 \mathrm{~kJ}$ & $120 / 150$ & $2.1 / 2.1$ & $120 / 150$ & $2.1 / 2.1$ & $80 / 100$ & $1.1 / 1.1$ & $40 / 50$ & 1.1 \\
\hline $3500 \mathrm{~kJ}$ & $240 / 270$ & $2.1 / 2.1$ & $240 / 270$ & $2.1 / 2.1$ & $160 / 180$ & $1.1 / 1.1$ & $80 / 90$ & 1.1 \\
\hline $5000 \mathrm{~kJ}$ & $300 / 420$ & $2.1 / 2.1$ & $300 / 420$ & $2.1 / 2.1$ & $200 / 280$ & $1.1 / 1.1$ & $50 / 70$ & 1.1 \\
\hline
\end{tabular}

*Note : The energy dissipating devices on lateral support ropes are for conservative design.

Table 4. Geometrical Information of Three Models

\begin{tabular}{ccccccc}
\hline Model & $L_{\mathrm{d}}(\mathrm{m})$ & $H_{\mathrm{p}}(\mathrm{m})$ & $U_{\mathrm{h}}(\mathrm{m})$ & $H_{\mathrm{d}}(\mathrm{m})$ & $\beta\left(^{\circ}\right)$ & $n_{\mathrm{t}}$ \\
\hline $2000 \mathrm{~kJ}$ & 9.00 & 5.50 & 7.50 & 6.25 & 10 & 24 \\
$3500 \mathrm{~kJ}$ & 9.00 & 6.10 & 7.50 & 6.25 & 10 & 24 \\
$5000 \mathrm{~kJ}$ & 10.00 & 5.16 & 10.00 & 5.00 & 0 & 25 \\
\hline
\end{tabular}

Table 5. Component Specifications

\begin{tabular}{ccccc}
\hline \multicolumn{2}{c}{ Component } & $2000 \mathrm{~kJ}$ & $3500 \mathrm{~kJ}$ & $5000 \mathrm{~kJ}$ \\
\hline Ring net & $\mathrm{R} 16 / 3 / 300$ & $\mathrm{R} 19 / 3 / 300$ & $\mathrm{R} 19 / 3 / 300$ \\
\hline & Upper support & $3 \varphi 22$ & $5 \varphi 22$ & $8 \varphi 22$ \\
& Lower support & $3 \varphi 22$ & $5 \varphi 22$ & $8 \varphi 22$ \\
$\begin{array}{c}\text { Steel wire } \\
\text { rope }\end{array}$ & Lateral support & $1 \varphi 22$ & $1 \varphi 22$ & $1 \varphi 22$ \\
& Lateral anchor & $1 \varphi 22$ & $2 \varphi 22$ & $2 \varphi 22$ \\
& Upslope anchor & $1 \varphi 22$ & $2 \varphi 22$ & $4 \varphi 22$ \\
\hline Steel post & & $\mathrm{HW} 200 \times 200 \times 8 \times 12$ & $\mathrm{HW} 250 \times 250 \times 9 \times 14$ & $\square \mathrm{HW} 250 \times 250 \times 20$ \\
\hline
\end{tabular}




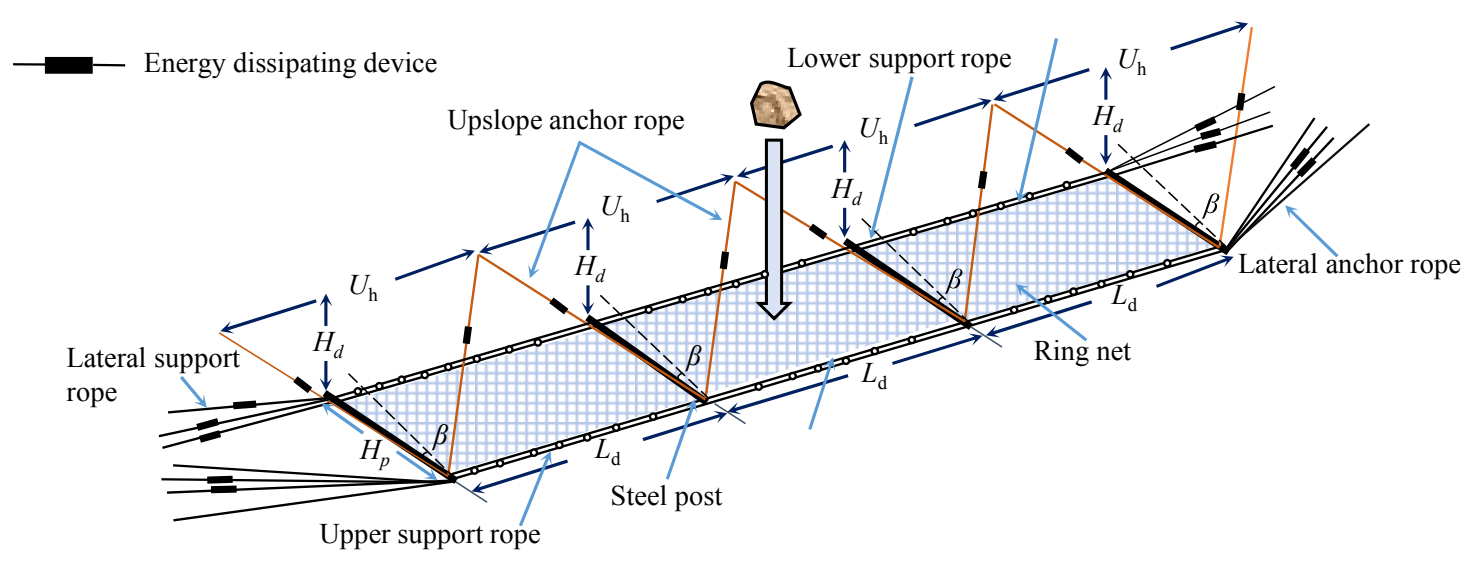

Figure 17. Layout of Three Models

\subsubsection{Numerical Models}

The computer program LS-DYNA [32] has been employed for the numerical simulation of flexible barrier system. The detailed finite element model can be found in the literature [2, 3]. The Hughes-Liu beam element combined with material type 24, which has the characteristics of piecewise linear plastic, were adopted to model steel-wire rings and energy dissipating devices. The steel posts were modeled by the user-defined integration beam element using I-shape section and the material type 3 with elastic-perfectly-plastic behavior. The steel posts were able to rotate freely in the vertical plane and rotate finitely in the horizontal plane [2, 3, 8]. A special element called seatbelt was adopted to model the support ropes sliding through the post end. The automatic contact of beam to surface was adopted to simulate the actual contact between the rockfall and the steel-wire ring net. The automatic general contact was adopted to simulate the contact between steel-wire rings, support ropes and shackles. Mass-scaling technique was adopted to enhance computational efficiency. In the explicit dynamic analysis, the time step was set to $0.00001 \mathrm{~s}$ so that the additional mass was less than 5\% [32]. Meanwhile, the dynamic relaxation technique has been used to consider the initial stress and the initial deflection due to gravity loads on the systems. The rockfall and steel-wire ring nets were set to be closely at the initial state, and the impact energy of rockfall was considered by modifying its initial velocity. In order to reduce the computational cost and balance the stability of energy state, the termination time was set to $1.0 \mathrm{~s}$ uniformly. The material parameters adopted in the numerical model were listed in Table 6.

Table 6. Material Parameters of Component

\begin{tabular}{ccccc}
\hline Component & Density & $\begin{array}{c}\text { Poisson's } \\
\text { ratio }\end{array}$ & Elastic modulus & Yield stress \\
\hline Steel wire ring net & $7900 \mathrm{~kg} \cdot \mathrm{m}^{-3}$ & 0.3 & $1.5 \times 10^{5} \mathrm{MPa}$ & $1770 \mathrm{MPa}$ \\
Steel wire rope & $7900 \mathrm{~kg} \cdot \mathrm{m}^{-3}$ & 0.3 & $1.2 \times 10^{5} \mathrm{MPa}$ & $1770 \mathrm{MPa}$ \\
Steel post & $7900 \mathrm{~kg} \cdot \mathrm{m}^{-3}$ & 0.3 & $2.0 \times 10^{5} \mathrm{MPa}$ & $235 \mathrm{MPa}$ \\
Energy dissipating device & $7900 \mathrm{~kg} \cdot \mathrm{m}^{-3}$ & 0.3 & $1.5 \times 10^{5} \mathrm{MPa}$ & - \\
Rockfall & $2500 \mathrm{~kg} \cdot \mathrm{m}^{-3}$ & 0.2 & $2.0 \times 10^{4} \mathrm{MPa}$ & - \\
\hline
\end{tabular}




\subsubsection{Result Comparison and Discussion}

The numerical simulations show that the three systems can stop the falling rocks successfully without structural damage. During the impact process, the support ropes slid on the post end smoothly, without interference and buckling of steel posts. The final deformed shapes of the models were shown in Figure 18. The parameters $s, \Delta_{1 \mathrm{a}}, \Delta_{2 \mathrm{~s}}$ and $\Delta_{3 \mathrm{n}}$ of each model under the impact of rockfall are plotted in Figure 19. Although each model subjected to different impact energy, the maximum elongation $S$ max were very close to each other, because the deflection of each component was designed with same criterion. From Figure 19b, although the deflection $\Delta_{1}$ a due to support structure of each model was largely different, its contribution on the total deflection $s$ was very low. The deflection $\Delta 2$ s duo to support ropes of each model was close to each other, as shown in Figure $19 \mathrm{c}$, because the working force on the energy dissipating devices connected to the support ropes were well controlled at the same level. Although the performance of these energy dissipating devices were different, the design tensile deformations were consistent, as shown in Table 3. The deflection $\Delta 3 \mathrm{n}$ due to ring net of each model also agreed with each other, seen in Figure $19 \mathrm{~d}$. The behaviors of the ring nets in the three models show in same trend as reported in the puncturing tests of 17 groups of steel-wire ring nets. It is indicated that $\Delta 3 \mathrm{n}$ is less relevant to the configurations of the flexible rockfall barrier.

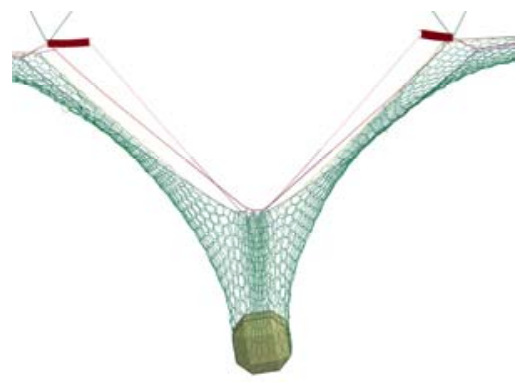

(a) $2000 \mathrm{~kJ}$ System

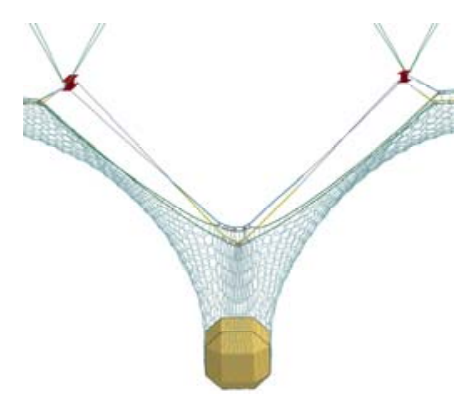

(b) $3500 \mathrm{~kJ}$ System

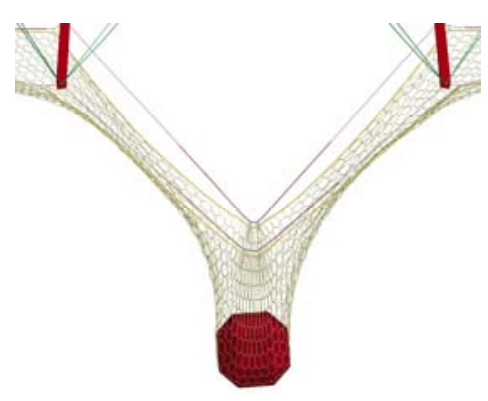

(c) $5000 \mathrm{~kJ}$ System

Figure 18. Final Deformed Shapes of Three Models

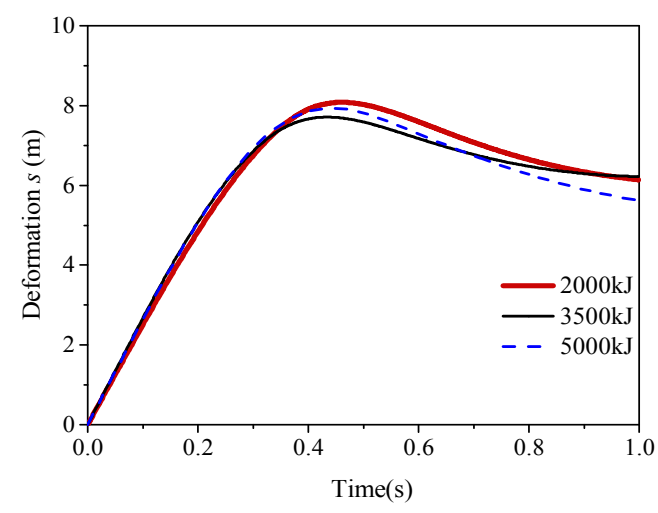

(a) Total Deflection $s$ of System



(b) Deflection $\Delta_{1}$ a of Support Structure 


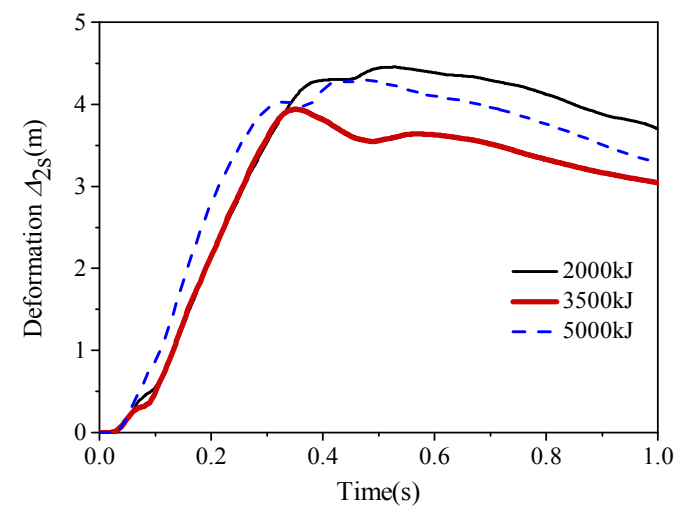

(c) Sliding Movement $\Delta 2$ s of Support Rope

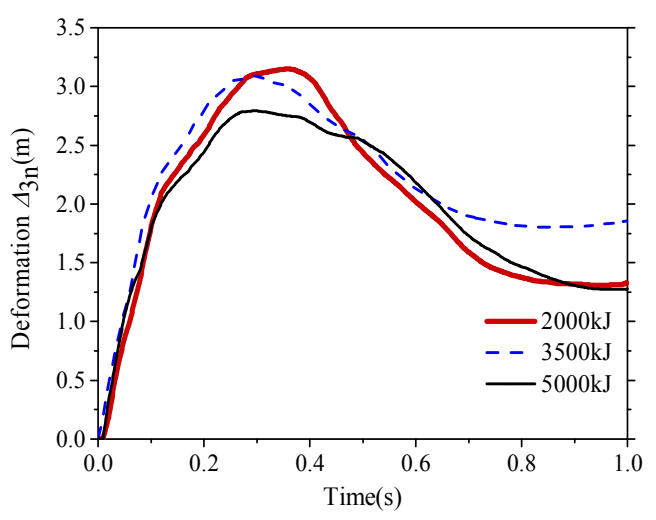

(d) Puncturing Deflection $\Delta 3$ of Ring Net

Figure 19. System Elongations and Deflections of Components

When using the proposed analytical solution, the ultimate elongations of the steel-wire rings in 'bypassing length' are $3.28 \mathrm{~m}, 3.28 \mathrm{~m}$ and $3.42 \mathrm{~m}$ respectively according to Eq. 8 . The elongation $\delta_{3}$ of the energy dissipating device of support rope all are $2.1 \mathrm{~m}$ according to Eq. 4 . As $\delta_{3}<\Delta_{\text {trans }}, \Delta_{2 \mathrm{~s}}$ could be calculated by Eq. 7 and Eq. 9. The deflections $\Delta_{1 \mathrm{a}}$ and $\Delta_{3 \mathrm{n}}$ are calculated by Eq. 6 and Eq. 10 and verified by the numerical simulation results. The parameters involved in the analytic method are listed in Table 7.

Table 7. Parameters used in Analytical Solution

\begin{tabular}{cccccccccc}
\hline Model & $L_{0}(\mathrm{~m})$ & $\mu_{1}$ & $\mu_{2}$ & $w_{\mathrm{s}}(\mathrm{m})$ & $h_{\mathrm{c}}(\mathrm{m})$ & $\mu_{3 \mathrm{~L}}$ & $\mu_{3 \mathrm{R}}$ & $n_{\text {toal }}$ & $n_{\text {diagnoal }}$ \\
\hline $2000 \mathrm{~kJ}$ & 8.45 & 1.0 & 0.20 & 1.49 & 0.37 & 1.0 & 1.0 & 27 & 7 \\
$3500 \mathrm{~kJ}$ & 8.78 & 1.0 & 0.75 & 1.78 & 0.44 & 1.0 & 1.0 & 28 & 8 \\
$5000 \mathrm{~kJ}$ & 8.67 & 1.0 & 0.75 & 1.90 & 0.47 & 1.0 & 1.0 & 26 & 9 \\
\hline
\end{tabular}

As shown in Table $8, \varphi_{\mathrm{c} 1}$ and $\varphi_{\mathrm{c} 2}$ of each model are in the range of 0.54 to 0.60 and 0.89 to 0.92 respectively. Compared with the above statistical values, the maximum difference was $9.1 \%$ and $2.2 \%$ respectively. Thus, the values of $\varphi_{\mathrm{c} 1}$ and $\varphi_{\mathrm{c} 2}$ are reasonable and acceptable.

\section{Table 8. Tensile Deformation Coefficient}

\begin{tabular}{ccccccc}
\hline Model & $l_{\mathrm{n} 1}(\mathrm{~m})$ & $l_{1}(\mathrm{~m})$ & $\varphi_{\mathrm{c} 1}$ & $l_{\ln 2}(\mathrm{~m})$ & $l_{2}(\mathrm{~m})$ & $\varphi_{\mathrm{c} 2}$ \\
\hline $2000 \mathrm{~kJ}$ & 1.79 & 3.30 & 0.54 & 8.57 & 9.42 & 0.92 \\
$3500 \mathrm{~kJ}$ & 2.15 & 3.77 & 0.57 & 8.48 & 9.42 & 0.90 \\
$5000 \mathrm{~kJ}$ & 2.28 & 3.77 & 0.60 & 7.55 & 8.48 & 0.89 \\
\hline
\end{tabular}


Accordingly, the analytical deflection $\Delta_{1 \mathrm{a}}, \Delta_{2 \mathrm{~s}}$ and $\Delta_{3 \mathrm{n}}$ of each model can be calculated from Eqs. (6, 7, 10). The result indicated as 'Analytical 1' in Table 9 is the analytical deflection when the parameters of $\mu_{1} \delta_{1}, \mu_{2} \delta_{2}, \mu_{3} \delta_{3}$ and $\mu_{3 \mathrm{R}} \delta_{3}$ obtained from numerical simulations are adopted; while the result 'Analytical 2' in Table 9 is the analytical deflection when the statistical value of $\mu_{1}, \mu_{2}$, $\mu_{3 \mathrm{~L}}, \mu_{3 \mathrm{R}}$ shown in Table 7 are adopted. The deflection of each component obtained from numerical simulations directly is also given in Table 9.

Compared with the results from numerical simulation, the analytic solution reproduces the spatial relationship of the system after impact with acceptable accuracy. The difference of system elongation $s$ in 'Analytical 2' is slightly higher than that in 'Analytical 1', because $\mu$ is a statistic value in the calculation of 'Analytical 2'. Generally speaking, the accuracy of 'Analytical 2' is acceptable for practical applications. When calculating 'Analytical 1', the data of the elongation of energy dissipating devices are derived from the numerical results directly and therefore, this set results are more accurate. The differences mainly come from the approximation coefficients of deflection in the analytic method, such as the coefficient of ring deflection and the development factor $\varphi$, the $\operatorname{sag} f_{\mathrm{r}}$ of support ropes, the initial $\operatorname{sag} f_{\mathrm{n}}$ of the mesh, the neglection of the initial sag of the upslope anchor ropes and the approximation of the calculating diagrams. The results of large deflection analysis also show that $\Delta_{2 \mathrm{~s}}$ accounts for more than $50 \%$ of the total deflection of the system, which means that the sliding movement of support ropes has a significant influence on the buffering performance of the system.

Table 9. Result Comparison

\begin{tabular}{cccccccccccccc}
\hline \multirow{2}{*}{ Results } & \multicolumn{3}{c}{$\Delta_{\text {1a }}$} & \multicolumn{3}{c}{$\Delta_{\text {2s }}$} & \multicolumn{3}{c}{$\Delta_{3 \mathrm{n}}$} & \multicolumn{3}{c}{$S_{\max }$} \\
\cline { 2 - 13 } & 2000 & 3500 & 5000 & 2000 & 3500 & 5000 & 2000 & 3500 & 5000 & 2000 & 3500 & 5000 \\
\hline Simulation (m) & 0.49 & 0.69 & 0.83 & 4.45 & 3.94 & 4.30 & 3.15 & 3.09 & 2.80 & 8.09 & 7.71 & 7.93 \\
Analytical 1 (m) & 0.48 & 0.68 & 0.81 & 4.18 & 4.05 & 4.45 & 3.06 & 3.17 & 2.61 & 7.72 & 7.90 & 7.87 \\
Analytical 2 (m) & 0.47 & 0.72 & 0.81 & 4.10 & 4.01 & 4.26 & 3.06 & 3.17 & 2.61 & 7.63 & 7.90 & 7.68 \\
Error 1 (\%) & 2.0 & 1.4 & 2.4 & 6.0 & 2.8 & 3.5 & 2.9 & 2.6 & 6.8 & 4.5 & 0.6 & 0.8 \\
Error 2 (\%) & 4.1 & 4.3 & 2.4 & 7.9 & 1.8 & 0.9 & 2.9 & 2.6 & 6.8 & 5.7 & 2.5 & 3.2 \\
\hline
\end{tabular}

\section{CONCLUSIONS}

The flexible rockfall barrier system exhibits large deflection and complex contact behaviors such that sophisticated finite element method and full-scale test are widely used to design this kind of structures, which causes inconvenient for most engineers. In this paper, a simple analytical method is proposed for fast evaluation of the performance of the flexible rockfall barrier system on the basis of system deformation characteristics observed in the full-scale impact tests and, the component deformation characteristics from component tests. The proposed analytical solution is verified by the experimental tests and numerical simulation. The examples show that the proposed method has reasonable accuracy and therefore it is acceptable for practical use. 
In summary, the following conclusions could be made from this paper:

(1) The large deflection of flexible rockfall barrier is caused by several factors such as the puncturing deflection of steel-wire ring net, the elongation of energy dissipating device, the sliding movement of support rope and the deflection of support structure. The puncturing deflection of steel-wire ring net is affected by its own configuration and therefore its deformed shape is relatively consistent and predictable. The second main part of total deflection of flexible barrier system is due to the elongation of energy dissipating device, relating to the work efficiency of energy dissipating device.

(2) An analytical method for prediction of the large deflection of flexible rockfall barrier is established based on the linear superposition of the deflection $\Delta_{1}$ of support structure, the sliding movement $\Delta 2 \mathrm{~s}$ of support rope, the puncturing deflection $\Delta_{3 \mathrm{n}}$ of steel-wire ring net and the sags of ropes and mesh. The analytical solution of each component has been established based on the spatial geometry relationship. The validity of the analytic solution has been verified by the results of 17 groups of puncturing tests on steel-wire ring net and numerical simulation of three flexible barrier systems. It should be pointed out that the sliding movement of support ropes has a significant influence on the large deflection of the system.

For the typical flexible rockfall barrier system shown in this paper, the proposed analytic method can be used to predict the maximum system deflection effectively. Thus, this method can be used to quickly design the system configuration on the basis of the acceptable maximum deflection and the protection energy requirement. It should be pointed out that if the structural system form is different from that studied in this paper, the proposed equations should be revised with similar procedure. The relevant parameters need to be updated with test results accordingly. The part two of this paper will further verify the proposed method by full-scale test of a flexible barrier system.

\section{ACKNOWLEDGMENTS}

The authors are grateful for financial support from the National Natural Science Foundation of China under Grant No. 51678504 and No. 51408498, Department of Science and Technology of Sichuan Province under Grant No. 2018JY0029, Open Fund of National Engineering Laboratory for Bridge Structure Safety Technology under Grant No.310821151102, and the Fund of State Key Laboratory of Geohazard Prevention and Geoenvironment Protection under Grant No.SKLGP2016K013. The last author is grateful for financial support the Innovation and Technology Fund of the Hong Kong SAR Government for the project "Development of an Energy Absorbing Device for Flexible Rock-Fall Barriers (ITS/059/16FP)”.

\section{REFERENCES}

[1] EOTA. Guideline for European technical approval of falling rock protection kits (ETAG 027), 2012, Brussels.

[2] Zhao Shichun, Yu Zhixiang, Zhao Lei, et al. "Damage mechanism of rockfall barriers under strong impact loading”, Journal of Engineering Mechanics, 2016, Vol. 33, No. 10, pp. 24-34.

[3] Zhao Shichun, Yu Zhixiang, Wei Tao, et al. "Test study of force mechanism and numerical 
calculation of safety netting system [J]". Journal of China Civil Engineering Journal, 2013, Vol.46, No. 5, pp. 122-128.

[4] Gottardi G, Govoni L. "Full-scale Modelling of Falling Rock Protection Barriers". Journal of Rock Mechanics \& Rock Engineering, 2010, Vol. 43, No. 3, pp. 261-274.

[5] Peila D, Pelizza S, Sassudelli F. "Evaluation of Behaviour of Rockfall Restraining Nets by Full Scale Tests”. Journal of Rock Mechanics \& Rock Engineering, 1998, Vol. 31, No. 1, pp. $1-24$.

[6] Grassl H, Bartelt P A, Volkwein A, et al. "Experimental and numerical modeling of highly flexible rockfall protection barriers" Proceedings of 12th Panamerican Conference on Soil Mechanics and Geotechnical Engineering, Cambridge, Massachusetts, USA, 2003, Vol. $2589-2594$.

[7] Qi Xin. “The Mechanics Performance of Passive Flexible Protection Structure”. Southwest Jiaotong University, 2014.

[8] Escallón J P, Wendeler C, Chatzi E, et al. "Parameter identification of rockfall protection barrier components through an inverse formulation". Journal of Engineering Structures, 2014, Vol. 77, pp. 1-16.

[9] Kwan J S H,Chan S L, Cheuk J C Y, et al. "A case study on an open hillside landslide impacting on a flexible rockfall barrier at Jordan Valley", Journal of Hong Kong. Landslides, 2014, Vol. 11, No. 6, pp. 1-14.

[10] Escallón J P, Boetticher V, Wendeler C, et al. "Mechanics of chain-link wire nets with loose connections". Journal of Engineering Structures, 2015, Vol. 101, pp. 68-87.

[11] Morton E.C., Thompson A.G., Villaescusa E. "Testing and analysis of steel wire mesh for mining applications of rock surface support[J]". Proceedings of 5thWorld Congress on Computational Mechanics, Vienna, Austria.

[12] Gentilini C, Gottardi G, Govoni L, et al. "Design of falling rock protection barriers using numerical models". Journal of Engineering Structures, 2013, Vol.50, No. 3, pp. 96-106.

[13] Nicot F., Cambou B., and Mazzoleni G. "Design of Rockfall Restraining Nets from a Discrete Element Modeling”.Journal of Rock Mechanics and Rock Engineering. 2001, Vol. 34, No. 2, pp. 99-118.

[14] Bertrand D, Trad A, Limam A, et al. "Full-Scale Dynamic Analysis of an Innovative Rockfall Fence Under Impact Using the Discrete Element Method: from the Local Scale to the Structure Scale”. Journal of Rock Mechanics \& Rock Engineering, 2012, Vol. 45, No. 5, pp. 885-900.

[15] Moon T, Oh J, Mun B. "Practical design of rockfall catchfence at urban area from a numerical analysis approach". Journal of Engineering Geology, 2014, Vol. 172, No. 5, pp. 41-56.

[16] Gentilini C, Govoni L, Miranda S D, et al. "Three-dimensional numerical modelling of falling rock protection barriers". Journal of Computers \& Geotechnics, 2012, Vol. 44, No. 44, pp. 58-72.

[17] Volkwein A. "Numerical modelling of flexible rockfall protection systems". Journal of American Society of Civil Engineers, 2013, Vol. 11, No. 179, pp. 1-11.

[18] De Miranda, S., Gentilini, C., Gottardi, G., Govoni, L., Mentani, A., Ubertini, F. "Virtual testing of existing semi-rigid rockfall protection barriers". Journal of Engineering Structures, 2015, Vol. 85, pp. 83-94.

[19] Govoni, L., de Miranda, S., Gentilini, C., Gottardi, G., Ubertini, F. "Modelling of falling rock 
protection barriers" Journal of Physical Modelling in Geotechnics, 2011, Vol. 11, No. 4, pp. 126-137.

[20] De Miranda, S., Gentilini, C., Gottardi, G., Govoni, L., Ubertini, F., "A simple model to simulate the full-scale behaviour of falling rock protection barriers Physical Modelling in Geotechnics",Proceedings of the 7th International Conference on Physical Modelling in Geotechnics 2010, Vol. 2, pp. 1247-1252.

[21] Qiao Wentao, An Qi, Zhao Mingshan, et al., "Experimental study on the fundamental mechanical features of cable-supported ribbed beam composite slab structure", Advanced Steel Construction, 2017, Vol. 13, No. 2, pp. 96-116.

[22] Guo Jiamin, Yuan Xingfei, Xiong Zhixin, et al., "Force finding of suspended-domes using back propagation (BP) algorithm”, Advanced Steel Construction, 2016, Vol. 12, No. 1, pp. 17-31.

[23] Luo Bin, Guo Zhengxing, Chen Xiangnan, et al., "Static equilibrium form-finding analysis of cable-strut system based on nonlinear dynamic finite element method", Advanced Steel Construction, 2015, Vol. 11, No. 4, pp. 452-468.

[24] Escallón J P, Wendeler C., "Numerical simulations of quasi-static and rockfall impact tests of ultra-high strength steel wire-ring nets using Abaqus/Explicit”, 2013 SIMULIA community conference, 2013.

[25] Castanon-Jano L, Blanco-Fernandez E., "Castro-Fresno D, et al Energy Dissipating Devices in Falling Rock Protection Barriers", Journal of Rock Mechanics \& Rock Engineering, 2017, Vol 50, pp. 1-17.

[26] J.J. del Coz Díaz,P.J. García Nieto , D. Castro-Fresno , J. Rodríguez Hernández .,"Nonlinear explicit analysis and study of the behaviour of a new ring-type brake energy dissipator by FEM and experimental comparison", Journal of Applied Mathematics and Computation 2010, Vol. 216, No. 5, pp. 1571-1582.

[27] Dhakal S, Bhandary N P, Yatabe R, et al.," Numerical and analytical investigation towards performance enhancement of a newly developed rockfall protective cable-net structure", Journal of Natural Hazards \& Earth System Sciences, 2012, Vol. 12, No. 4, pp. 1135-1149.

[28] D. Castro-Fresno, J.J. del Coz Diaz, L.A. López, P.J. García Nieto., "Evaluation of the resistant capacity of cable nets using the finite element method and experimental validation", Engineering Geology, 2008, Vol. 100, No. 1-2, pp. 1-10.

[29] Grassl H, Volkwein A, Anderheggen E, et al., "Steel-net Rockfall Protection - Experimental And Numerical Simulation", Seventh international conference on structures under shock and impact. Montreal, Canada, pp 143-153.

[30] Muhunthan, B., H. Radhakrishnan, "Finite Element Analysis of Hybrid Barrier for Rock Fall Slope Protection", Final Report, Department of Civil and Environmental Engineering, Washington State University, 2007.

[31] GB/T 20118-2006, Steel wire ropes for general purpose, Standardization Administration of the People's Republic of China, Beijing, 2006.

[32] Livermore software technology corporation (LSTC), "LS-DYNA keyword user's manual volume I", 2007. 